\title{
Properties of multilayered and multicomponent nitride alloys from first principles
}

\author{
Fei Wang
}


Fei Wang was involved in DocMASE Programme (the Joint European Doctoral Programme in Material Science and Engineering). The study is a collaboration between Theoretical Physics Division, Department of Physics, Chemistry, and Biology (IFM) Linköping University, SE-581 83 Linköping, Sweden and Functional Materials Division, Department of Material Science and Engineering, Saarland University, D-66123 Saarbrücken, Germany.

(C) Fei Wang

ISBN 978-91-7685-382-5

ISSN 0345-7524

Printed by LiU-Tryck 2018 
To my family 



\section{Abstract}

This thesis is a theoretical exploration of properties of multilayered and multicomponent nitride alloys, in particular their mixing thermodynamics and elastic behaviors. Systematic investigation of properties of a large class of materials, such as the multicomponent nitride solid solutions, is in line with the modern approach of high-throughput search of novel materials. In this thesis we benchmark and utilize simple but efficient methodological frameworks in predicting mixing thermodynamics, Young's moduli distribution of multilayer alloys and the linear thermal expansion of quaternary nitride solid solutions.

We demonstrate by accurate ab-initio calculations that $\mathrm{Ti}_{1-x} \mathrm{Al}_{x} \mathrm{~N}$ solid solution is stabilized by interfacial effects if it is coherently sandwiched between TiN layers along (001). For $\mathrm{TiN} / \mathrm{AlN}$ and $\mathrm{ZrN} / \mathrm{AlN}$ multilayers we show higher thermodynamic stability with semicoherent interfaces than with isostructural coherent ones.

Accurate 0 Kelvin elastic constants of cubic $\mathrm{Ti}_{x} \mathrm{X}_{y} \mathrm{Al}_{1-x-y} \mathrm{~N}$ (X=Zr, Hf, Nb, $\mathrm{V}, \mathrm{Ta}$ ) solid solutions and their multilayers are derived and an analytic comparison of strengths and ductility are presented to reveal the potential of these materials in hard coating applications. The Young's moduli variation of the bulk materials has provided a reliable descriptor to screen the Young's moduli of coherent multilayers.

The Debye model is used to reveal the high-temperature thermodynamics and spinodal decomposition of $\mathrm{Ti}_{x} \mathrm{Nb}_{y} \mathrm{Al}_{1-x-y} \mathrm{~N}$. We show that though the effect of vibration is large on the mixing Gibbs free energy the local spinoal decomposition tendencies are not altered. A quasi-harmonic Debye model is benchmarked against results of molecular dynamics simulations in predicting the thermal expansion coefficients of $\mathrm{Ti}_{x} \mathrm{X}_{y} \mathrm{Al}_{1-x-y} \mathrm{~N}(\mathrm{X}=\mathrm{Zr}, \mathrm{Hf}, \mathrm{Nb}, \mathrm{V}, \mathrm{Ta})$. 



\section{Sammanfattning}

Denna avhandling är en teoretisk undersökning av egenskaperna hos multilager och multikomponentlegeringar av nitrider, särskilt deras blandningstermodynamik och elastiska egenskaper. Systematiska undersökningar av egenskaperna hos en stor materialfamilj, såsom fasta lösningar av multikomponentnitrider, ligger i linje med den moderna angreppsvinkeln av massundersökningar i sökandet efter nya material. I denna avhandling utvärderar och använder vi enkla men effektiva metodologiska ramverk för att förutsäga blandningstermodynamik, fördelning av Young's moduli multilager och den linjära termiska expansionen i kvaternära fasta lösningar av nitrider.

$\mathrm{Vi}$ visar med precisa ab-initio-beräkningar att en fast lösning av $\mathrm{Ti}_{1-x} \mathrm{Al}_{x} \mathrm{~N}$ stabiliseras av gränssnittseffekter om den placeras koherent mellan TiN-skikt längs med (001). För multilager av TiN/AlN och $\mathrm{ZrN} / \mathrm{AlN}$ påvisar vi högre termodynamisk stabilitet med semikoherenta gränsskikt än med isostrukturella koherenta. Precisa elastiska konstanter vid $0 \mathrm{~K}$ för kubiska fasta lösningar av $\mathrm{Ti}_{x} \mathrm{X}_{y} \mathrm{Al}_{1-x-y} \mathrm{~N}$ $(\mathrm{X}=\mathrm{Zr}, \mathrm{Hf}, \mathrm{Nb}, \mathrm{V}, \mathrm{Ta})$ och deras multilager beräknas och en analytisk jämförelse av deras hållfasthet och duktilitet presenteras för att visa dessa materials potential som hårda beläggningar. Variationen av Young's moduli materialen i bulk har gett en pålitlig deskriptor för att undersöka Young's moduli koherenta multilager.

Debye-modellen används för att undersöka hög-temperatur-termodynamiken och spinodalt sönderfall hos $\mathrm{Ti}_{x} \mathrm{Nb}_{y} \mathrm{Al}_{1-x-y} \mathrm{~N}$. Vi visar att trots att vibrationers effekt på Gibbs fria energi för blandning är stor påverkas inte de lokala tendenserna för spinodalt sönderfall. En kvasiharmonisk Debye-modell jämförs med resultat från molekyldynamiksimuleringar för att förutsäga utvidgningskoefficienter för $\mathrm{Ti}_{x} \mathrm{X}_{y} \mathrm{Al}_{1-x-y} \mathrm{~N}(\mathrm{X}=\mathrm{Zr}, \mathrm{Hf}, \mathrm{Nb}, \mathrm{V}, \mathrm{Ta})$. 



\section{Zusammenfassung}

Diese Arbeit ist eine theoretische Untersuchung der Eigenschaften von mehrschichtigen und mehrkomponentigen Nitridlegierungen, insbesondere deren MischungsThermodynamik und elastischen Verhalten. Eine systematische Untersuchung von Eigenschaften einer großen Klasse von Materialien, wie zum Beispiel fester Lösungen von Mehrkomponenten-Nitriden, ist im Einklang mit dem zeitgenössischen Hochdurchsatzverfahren für die Suche nach neuen Materialien. In dieser Arbeit benchmarken und nutzen wir einfache, aber effiziente methodische Frameworks zur Vorhersage der Mischungs-Thermodynamik, der Verteilung des Elastizitätsmoduls von Mehrschichtlegierungen und der linearen thermischen Ausdehnung von festen, quaternären Nitrid-Lösungen. Wir zeigen durch genaue Ab-initio-Berechnungen, dass $\mathrm{Ti}_{1-x} \mathrm{Al}_{x} \mathrm{~N}$ Mischkristalle durch Grenzflächenwirkungen stabilisiert werden, wenn sie kohärent zwischen TiN Schichten entlang (001) sandwichartig angeordnet sind. Die genauen elastischen Konstanten von kubischen $\mathrm{Ti}_{x} \mathrm{X}_{y} \mathrm{Al}_{1-x-y} \mathrm{~N}(\mathrm{X}=\mathrm{Zr}$, Hf, Nb, V, Ta) Mischkristallen und deren Mehrfachschichten bei 0 Kelvin werden abgeleitet und ein analytischer Vergleich der Festigkeit und Duktilität zeigt das Potential dieser Materialien in Hartbeschichtungsanwendungen. Das Debye-Modell wird verwendet, um die Hochtemperatur-Thermodynamik und die spinodale Entmischung von $\mathrm{Ti}_{x} \mathrm{Nb}_{y} \mathrm{Al}_{1-x-y} \mathrm{~N}$ aufzudecken. Wir zeigen, dass sich die lokale Tendenzen zur spinodalen Entmischung nicht ändern, obwohl die Wirkung von Vibrationen auf die Gibbs-Energie großist. Ein quasi-harmonisches Debye-Modell wird gegen die Ergebnisse von Moleküldynamik-Simulationen gebenchmarkt, um die thermische Ausdehnungskoeffizienten von $\mathrm{Ti}_{x} \mathrm{X}_{y} \mathrm{Al}_{1-x-y} \mathrm{~N}(\mathrm{X}=\mathrm{Zr}, \mathrm{Hf}, \mathrm{Nb}, \mathrm{V}$, Ta) vorherzusagen. 



\section{Populärvetenskaplig sammanfattning}

Industrin kräver ständig utveckling inom materialbearbetning för att utveckla innovativa produkter och stärka sin marknadsposition. Beläggningsmaterials hög temperaturprestanda har en enorm påverkan påskärverktygsindustrin. Ett materials hårdhet, strukturella stabilitet vid höga temperaturer och oxidationsmotstånd är nyckelstorheter för att det ska kunna användas i krävande miljöer. Moderna hårda beläggningsmaterial förväntas ha en hårdhet omkring 30-40 GPa och vara strukturellt stabila upp till en arbetstemperatur på $1200-1500^{\circ} \mathrm{C}$. Övergångsmetallnitrider(TiN, ZrN, HfN, NbN, VN, TaN) och deras legeringar definierar materialklassen med potential som hårda beläggningar.

Alla systematiska teoretiska undersökningar av utformningsstragier i klassen övergångsmetallnitrider använder datorer i ett slags "test och försök", med bonusen att fysiken bakom resultaten blottläggs. Detta är i linje med det moderna mass undersöknings-baserade sökandet efter nya material. Kemisk utformning såsom multikomponentlegering tillåter en att använda kombinationer av grundämnen från det periodiska systemet. Strukturell formgivning såsom att göra multilager innebär att material läggs mellan varandra vilket leder till att termisk stabilitet och materialets elasticitet kan förändras av ömsesidig växelverkan mellan materialen.

I min forskning har mitt mål varit att hitta och förklara trender i termisk stabilitet och elastiska egenskaper hos multilager och multikomponentlegeringar av nitrider. Jag har undersökt högtemperaturtermodynamiken i $\mathrm{Ti}_{x} \mathrm{Nb}_{y} \mathrm{Al}_{1-x-y} \mathrm{~N}$. Genom att använda en koherent multilagerstruktur av TiN och $\operatorname{Ti}_{1-x} \mathrm{Al}_{x} \mathrm{~N}$ har jag visat att gränsskiktseffekter stabiliserar $\mathrm{Ti}_{1-x} \mathrm{Al}_{x} \mathrm{~N}$-legeringen. Jag har beräknat de elastiska konstanterna för kubiska legeringar av $\mathrm{Ti}_{x} \mathrm{X}_{y} \mathrm{Al}_{1-x-y} \mathrm{~N}(\mathrm{X}=\mathrm{Zr}, \mathrm{Hf}$, $\mathrm{Nb}, \mathrm{V}, \mathrm{Ta}$ ) och deras multilager och gjort en analytisk jämförelse av hållfasthet och duktilitet för att utforska dessa materials potential som hårda beläggningar. Pågrund av dessa uppgifters komplexitet behövde jag utvärdera och använda enkla metoder istället för tids- och resurskrävande molekyldynamiksimuleringar. Jag har visat att en linjär elastisk modell av multilager är tillräcklig för att diskutera 
hållfastheten hos nitrid-multilager med olika ytorienteringar. Vidare har en kvasiharmonisk approximation av atomiska vibrationer visat sig vara tillräcklig för att förutsäga den termiska expansionen av multikomponentnitridlegeringar.

Min avhandling visar att moderna atomistiska simuleringsmetoder kombinerade med kontrollerade fysiska approximationer för teoretiska undersökningar till framkanten av utformningen av nyskapande teknologiska material för att befästa mottot "Rätt material för rätt tillämpning". 
This thesis is a result of my doctoral studies carried out in Theoretical Physics Division at the Department of Physics, Chemistry, and Biology at Linköping University(Sweden) and Functional Materials Division at the Department of Material Science and Engineering at Saarland University(Germany) from Oct,2012 to Feb,2018. During this time, I have spent more than 6 months in Saarland University.

My work was part of the Joint European Doctoral Programme in Material Science and Engineering(DocMASE). The research was also partially supported by the Swedish Foundation for Strategic Research (SSF) project SRL Grant No. 10-0026.

All the theoretical calculations have been carried out using supercomputer resources provided by the Swedish National Infrastructure for Computing(SNIC) at the National Supercomputer Center(NSC) and the Center for High-Performance Computing(PDC). 



\section{Acknowledgements}

- My supervisor, Dr. Ferenc Tasnádi, for giving me the oppotunity to do this journey, for the help with the start, for all the support and guidance during my studies. It has been a fantastic experience to work with you!

- My co-supervisor, Prof. Igor Abrikosov, for your support, encouragement and guidance, for sharing enormous amount of knowledge and invaluable contributions in different projects.

- My supervisor at Saarland University, Prof. Frank Mücklich, for providing me the oppotunity to live and work in wonderful Saarbrücken.

- Prof. Magnus Odén, for all the support in understanding materials science from experimental point of view and suggestions over these years.

- Dr. Flavio Soldera for solving all the problems in Saarbrücken, for having many unforgettable DocMASE summer schools.

- Special thanks to all my coauthors who I have had the pleasure to work with, especially Dr. Kumar Yalamanchili, Dr. Jianqiang Zhu, for your knowledge in experimental matters and our fruitful discussion and collaboration.

- All the colleagues in Theoretical Physics group and Nanostructured Materials group, for always being helpful and open for discussions.

- Warmest thanks to morning coffee group, for providing company and funny topics which were always entertaining, for all the activities we have had. It has been a lot of fun.

- Aylin Atakan and Dr. Isabella Schramm, for being such great friend with me. I really had a good time with you. 
- A distinguished important thank to my parents, who have always supported, encouraged and believed in me; my husband Chao, I would never come to this far without you; My son, Guoguo, who makes me feel really lucky. I am happy to have all of you in my life.

\section{王菲}

Fei Wang

Linköping, 2018 
1 Introduction 1

1.1 Theoretical material science . . . . . . . . . . . . . . . . . . 1

1.2 Aim of the thesis . . . . . . . . . . . . . . . . 2

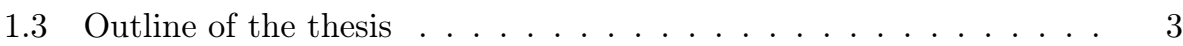

2 Hard coating nitrides 5

2.1 Binary nitrides . . . . . . . . . . . . . . . . . 6

2.2 Ternary pseudo-binary nitride alloys . . . . . . . . . . . . . 8

2.3 Quaternary nitride alloys ................. 11

2.4 Multilayers ... . . . . . . . . . . . . . . 11

3 Structure modeling of alloys $\quad 13$

3.1 Configurational disorder in alloys . . . . . . . . . . . . . . . 13

3.2 The special quasi-random structure (SQS) approach . . . . . . . . 14

3.2.1 Modeling multilayered alloys . . . . . . . . . . . . . 15

3.3 The Coherent Potential Approximation (CPA) . . . . . . . . . . 17

4 Mixing thermodynamics and decomposition $\quad 19$

4.1 Gibbs free energy . . . . . . . . . . . . . . . . . . . . . 19

4.2 Mixing enthalpy in multilayers . . . . . . . . . . . . . . . 20

4.3 Gibbs free energy calculated with the Debye model . . . . . . . . . 23

4.4 Thermal expansion coefficient (TEC) . . . . . . . . . . . 25

5 Elastic properties $\quad \mathbf{2 7}$

5.1 Elastic properties of isotropic solids . . . . . . . . . . . . . 27

5.2 Elastic stiffness tensor . . . . . . . . . . . . . . . . . . 28

5.3 Elastic moduli of polycrystalline materials . . . . . . . . . . . 29

5.4 Elastic properties of cubic disordered structures . . . . . . . . . . 30

5.5 Elastic Young's modulus of multilayers . . . . . . . . . . . . . 31 
6 Density Functional Theory 33

6.1 Hohenberg-Kohn theorems . . . . . . . . . . . . . . . . . 34

6.2 Kohn-Sham equation . . . . . . . . . . . . . . . . . . . . 35

6.3 Exchange-correlation functionals . . . . . . . . . . . . 36

6.4 Basis sets . . . . . . . . . . . . . . . . . 36

$\begin{array}{lll}7 & \text { Results } & 39\end{array}$

7.1 Thermodynamics stability . . . . . . . . . . . . . . . 39

7.1.1 Mixing thermodynamics of cubic $\mathrm{Ti}_{1-x} \mathrm{Al}_{x} \mathrm{~N} / \mathrm{TiN}(001)$ mul-

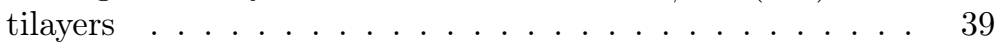

7.1.2 Thermal stability of $\mathrm{TiN} / \mathrm{AlN}$ and $\mathrm{ZrN} / \mathrm{AlN}$. . . . . . . . . 41

7.2 Elastic properties . . . . . . . . . . . . . . . . . . 43

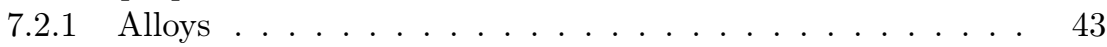

7.2.2 Multilayers .................... . . 44

7.3 Application of Debye model on multicomponent nitride alloys . . . 45

7.3.1 $\mathrm{Ti}_{x} \mathrm{Nb}_{y} \mathrm{Al}_{z} \mathrm{~N}$ alloys . . . . . . . . . . . . . . . 45

7.3.2 Thermal expansion coefficients of $\mathrm{Ti}_{1-x-y} \mathrm{X}_{y} \mathrm{Al}_{x} \mathrm{~N}(\mathrm{X}=\mathrm{Zr}$, $\mathrm{Hf}, \mathrm{Nb}, \mathrm{V}, \mathrm{Ta}) \ldots \ldots \ldots . \ldots . \ldots . \ldots 48$

8 Conclusions and Outlook $\quad 49$

$\begin{array}{ll}\text { Bibliography } & 51\end{array}$

List of included publications and my contribution $\quad 61$

$\begin{array}{lc}\text { Related, not included publications } & 63\end{array}$

$\begin{array}{ll}\text { Paper I } & 65\end{array}$

$\begin{array}{ll}\text { Paper II } & 73\end{array}$

$\begin{array}{ll}\text { Paper III } & 83\end{array}$

$\begin{array}{lr}\text { Paper IV } & 97\end{array}$

$\begin{array}{ll}\text { Paper V } & 109\end{array}$

$\begin{array}{ll}\text { Paper VI } & 121\end{array}$ 
CHAPTER 1

Introduction

\subsection{Theoretical material science}

Materials have always been imperative for humans to advance civilization. The material of choice is used to mark prehistorical periods, such as Stone Age, Bronze Age, Iron Age, and Steel Age. Evolving originally from metallurgy, material science became a scientific branch of its own. During the 19th and 20th centuries, it became a leading field of science with incorporating physics, chemistry, and engineering. Nowadays, on the basis of all the sophisticated technologies, when we are talking about materials, we also think of material's multi-functionality for next generation applications. It is motivated by the fact that the functionality of modern tools and devices, such as surface coatings, electrical and optical devices etc., are determined to a large extent by the material's properties on nanometer $\left(10^{-9} \mathrm{~m}\right)$ or atomic scale.

Through electronic-structure simulations, atomistic and quantum mechanical modeling of complex materials have became an important tool in the material's exploration, for example, the Material's Genome [1], Novel Materials Discovery (NOMAD) [2] etc. Experimental investigations are expensive and time consuming. The power of computer simulation, is that it can interpret and predict the properties of materials at arbitrary physical conditions (pressure, temperature). Of course, such theoretical studies have also limitations, (i) we investigate mostly perfect materials (not with the imperfections, defects) (ii) the solution of the quantum mechanical many-body problem requires approximations. Density-functional theory (DFT) has reached an appropriate level for many questions, but it is not completed yet. Nevertheless researchers have achieved great success in achieving thermodynamics accuracy, bridging length-scales and overcoming time-scales limitations. Modern theoretical material science faces with two main challenges: 


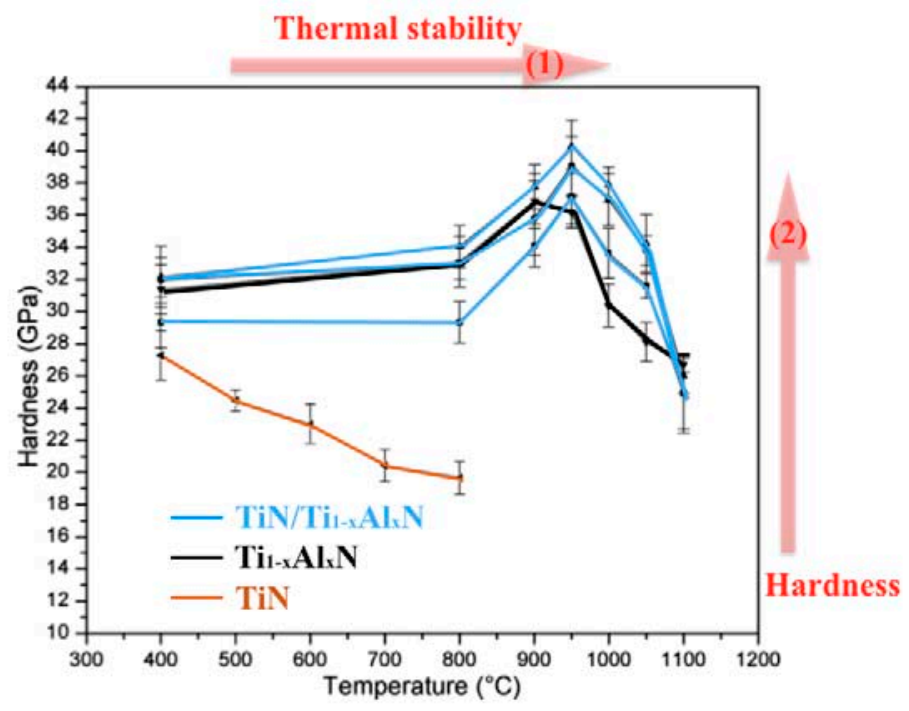

Figure 1.1. Hardness values of the as-deposited and heat treated monolithic and multilayered coatings. This figure is an adopted version of the figure in J. Appl. Phys. 108, 044312 (2010)

(A) It aims to provide a fundamental understanding of microscopic and macroscopic properties of materials, it wants to explain the experimentally observed properties and phenomena. For example, the mechanical properties of TiN, such as hardness is enhanced by alloying element $\mathrm{Al}$ or through a multilayer design [3]. The detailed arrangement and the movement of atoms and electrons (chemical bonds, phonons) brings insight on the experimental observation through a statistical description.

(B) It is utilized to discover novel materials or predict accurately and quantitatively the properties of systems that have not been investigated experimentally so far or cannot be investigated by experiments directly. For instance, the structure and properties of iron have been modeled theoretically at Earth-core conditions (around 300-350 GPa and 5000-6000 K) [4].

\subsection{Aim of the thesis}

Figure 1.1 plots the material's hardness (materials resistance against external force) of $\mathrm{TiN}, \mathrm{Ti}_{1-x} \mathrm{Al}_{x} \mathrm{~N}$ and $\mathrm{TiN} / \mathrm{Ti}_{1-x} \mathrm{Al}_{x} \mathrm{~N}$ [001] multilayers ( $x$ is a fraction of AlN) versus annealing temperature. It shows that the hardness of TiN decreases monotonously with the annealing temperature. In contrast the hardness of $\mathrm{Ti}_{1-x} \mathrm{Al}_{x} \mathrm{~N}$ alloy increases with the annealing temperature up to around $900{ }^{\circ} \mathrm{C}$. Around $900^{\circ} \mathrm{C}$ an anomalous increase of hardness is observed which is explained by the material's altered microstructure resulted by a (lattice) coherent spinodal decomposition. Cubic $\mathrm{B} 1 \mathrm{Ti}_{1-x} \mathrm{Al}_{x} \mathrm{~N}$ coherently decomposes into cubic $\mathrm{AlN}$ and 
cubic TiN phases. The hardness value decreases at higher temperatures as the cubic AlN phase transforms into the ground state hexagonal (wurtzite) structure [5]. Therefore an increased thermal stability of the cubic phase of AlN with respect its wurtzite phase is assumed to result in higher hardness value of the decomposed $\mathrm{Ti}_{1-x} \mathrm{Al}_{x} \mathrm{~N}$ at higher $\left(>1000{ }^{\circ} \mathrm{C}\right)$ temperatures. This hypothetical extension of hardness is shown with arrow (2) in Figure 1.1, both multicomponent alloying and artificial multilayer structuring might change the thermodynamic stability of the materials phases and result in altered hardness vs. temperature behavior. Materials elastic properties have indirect impact on hardness and therefore they are of distinct interest in searching for novel hard materials. The objective of this thesis is to give a fundamental exploration of thermodynamics and elastic properties of multilayered and multicomponent nitride alloys from three perspectives:

- What is the effect of lattice coherency and interfacial chemistry on the thermodynamics of multilayers. How interfacial effects influence the decomposition process of $\mathrm{Ti}_{1-x} \mathrm{Al}_{x} \mathrm{~N}$ if it is confined in a multilayer architecture.

- How multicomponent alloying improves material's thermal stability and elastic properties.

- Since the elastic energy distribution influences the microstructure of the decomposing solid solution through the anisotropic elastic (stiffness) constants, one has to develop an overview of the single crystal and polycrystalline elasticity of multicomponent nitrides alloys and for some of their multilayers.

The material class we focus on in this thesis is restricted to nitride solid solutions and multilayers with high potential for cutting tool applications. We investigate AlN, XN, $\mathrm{X}_{1-x} \mathrm{Al}_{x} \mathrm{~N}, \mathrm{X}_{1-x} \mathrm{Ti}_{x} \mathrm{~N}, \mathrm{Ti}_{x} \mathrm{X}_{y} \mathrm{Al}_{1-x-y} \mathrm{~N}$ (X=Ti, Zr, Hf, V, Nb, Ta), $\mathrm{TiN} / \mathrm{AlN}$ and $\mathrm{Ti}_{1-x} \mathrm{Al}_{x} \mathrm{~N} / \mathrm{TiN}$ etc.

\subsection{Outline of the thesis}

This thesis includes chapters with a comprehensive overview of the investigated materials, the applied theoretical approaches and the obtained results.

- Chapter 1 gives a brief overview of theoretical material science and the aim of this work.

- Chapter 2 provides an introduction to hard coating materials, as well as the ones of interest for this work: the binary nitrides, titanium nitride based ternary and quaternary nitride alloys and alloys in multilayers.

- Chapter 3 describes the applied methods for the structural modeling of random alloys and alloys in multilayers.

- Chapter 4 explains the mixing thermodynamics of alloys and multilayers.

- Chapter 5 explores the calculations of elastic properties in disordered alloys and alloys in multilayers. 
- Chapter 6 presents a short overview of the underlying approach of electronic structure calculations, which is density functional theory (DFT).

- Chapter 7 contains a summary of results presented in the included papers.

- Chapter 8 presents a short conclusion and an outlook for future research.

- The papers are included in the end of the thesis. 


\section{CHAPTER 2}

\section{Hard coating nitrides}

Coatings are usually micron $\left(10^{-6} \mathrm{~m}\right)$ thick layers on the surface of machining tools (drills, gears, etc.) and other devices. The purpose of applying coatings might be functional and decorative, or both. Coatings are applied to functionalize the surface properties of the raw material, such as thermal and electrical conductivity, optical reflectivity or corrosion and wear resistance. Since manufacturing industries have become increasingly dependent on automation, the critical demand for wear- and corrosion- resistant coatings has also expanded. In today's industries, the protective coatings, also known as hard coatings, were developed and used to improve the operational efficiency, reliability and the life time of cutting and machining tools. The global market for these coating systems is rising.

In 1969, a few microns thick titanium carbide TiC coatings were developed using chemical vapor deposition (CVD) technique to prevent the cutting tools start to oxidize at low temperatures [6]. During the last three decades transition metal nitrides and carbides have been developed as prominent hard coating materials as they offer extremely hard surfaces, low friction coefficient, excellent adhesion, favorable sliding characteristics, and relatively high electrical and thermal conductivity. These extraordinary properties could be explained after understanding the thermodynamic, the crystallographic and microstructural characteristics of these materials in connection with their microscopic electronic properties.

The industrial scaled PVD (physical vapor deposition) deposited TiN High Speed Steel (HSS) drill bits were introduced in 1982 [6]. Using physical vapor deposition one solved problems appeared in CVD grown coatings, such as the poor transverse rupture strength and toughness. However, the oxidation resistance of the achieved coatings were not satisfactory. In 1986 the first PVD Ti-Al-N coatings were reported with improved oxidation resistance and superior cutting performance compared to TiN [7], because of a peak in the hardness value around $900{ }^{\circ} \mathrm{C}[3]$. This age hardening phenomena starts to disappear rapidly at $950{ }^{\circ} \mathrm{C}$ 


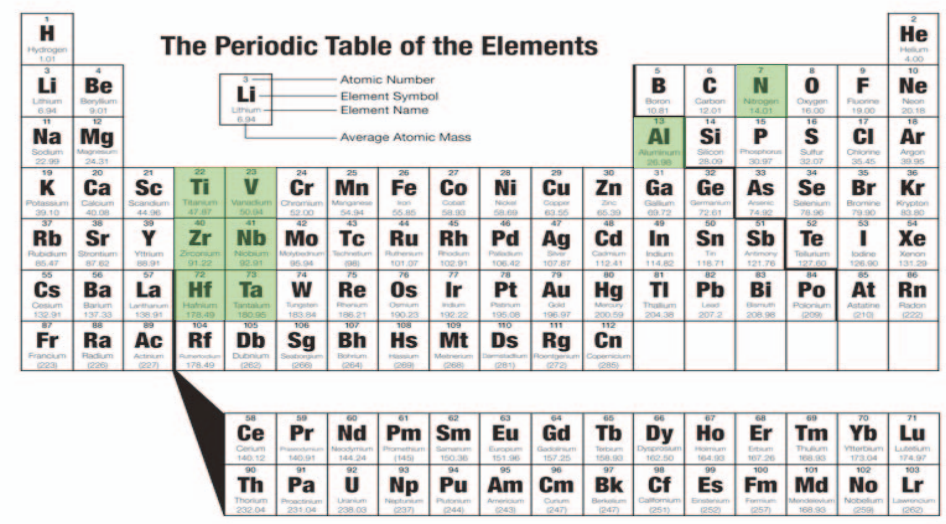

Figure 2.1. The periodic table of elements. Elements marked in green have been investigated in this work.

and above, which is the actual operation temperature of high-speed cutting tools for 10-15 minutes. This phenomenon of age hardening at elevated temperature is triggered by the self-organized nanostructuring of the solid solution as a result of spinodal decomposition. The metastable cubic Ti-Al-N decomposes coherently into cubic TiN and cubic AlN. At higher temperatures the ground state hexagonal phase of AlN phase hinders the presence of the cubic phase, which results in a significant hardness drop [5].

Multicomponent alloys and their multilayers as coatings have become highly interests in the past decades by their promise in fulfilling the need of cutting and machining tool industry for increased productivity and reliability. The physical properties of hard coating alloys can be engineered by altering the composition or making an artificial structuring of various phases on a microscopic scale. For example, in a multilayer form with different interface orientation.

\subsection{Binary nitrides}

The lattice parameters of the bellow described binary nitrides with cubic and hexagonal structures are summarized in Table 2.1 .

Aluminum nitride $(\mathrm{AlN})$ is a wide band gap $(6.2 \mathrm{eV})$ semiconductor material, mainly used in optical and electronic device applications [8]. The thermodynamically stable (hexagonal, B4) structure of AlN is illustrated in Figure 2.2 (a). It has lattice parameters $\mathrm{a}=3.11 \AA$ and $\mathrm{c}=4.98 \AA[9]$. AlN stabilizes in cubic structure with lattice parameter $\mathrm{a}=4.05 \AA$ at high pressure $(16.6 \mathrm{GPa})$ and temperature $[10,11]$. Cubic AlN phase can be grown as epitaxial film on Si substrates [12] or stabilized in the multilayer structure $\mathrm{TiN} / \mathrm{AlN}(001)$ [13]. It appears as metastable phase during the spinodal decomposition of cubic $\mathrm{B} 1 \mathrm{Ti}_{1-x} \mathrm{Al}_{x} \mathrm{~N}$ solid solution, which process is responsible for the age hardening of Ti-Al-N coatings $[3,5,14$, $15]$. 
Table 2.1. The lattice parameters $a(\AA)$ of binary nitrides with cubic and hexagonal structures

\begin{tabular}{|cc|}
\hline structure & $a(\AA)$ \\
\hline cubic (B1) AlN & 4.05 \\
hexagonal (B4) AlN & $a=3.11, c=4.98$ \\
\hline cubic (B1) TiN & 4.24 \\
\hline cubic (B1) ZrN & 4.58 \\
\hline cubic (B1) HfN & 4.53 \\
\hline cubic (B1) VN & 4.14 \\
hexagonal $\mathrm{V}_{2} \mathrm{~N}$ & $a=2.84, c=4.54$ \\
\hline cubic (B1) $\mathrm{NbN}_{\text {hexagonal } \mathrm{Nb}_{2} \mathrm{~N}}$ & $a=3.05, c=5.01$ \\
\hline cubic $(\mathrm{B} 1) \mathrm{TaN}^{\mathrm{N} N}$ & 4.36 \\
hexagonal $\mathrm{Ta}_{2} \mathrm{~N}$ & $a=5.19, c=2.91$ \\
\hline
\end{tabular}

Titanium nitride (TiN) is an extremely hard material with cubic B1 structure as shown in Figure 2.2 (b), it has a lattice parameter $\mathrm{a}=4.24 \AA$ [16]. It has high hardness $\sim 26-30 \mathrm{GPa}[3,17]$ and offers excellent protection against abrasive wear. Therefore, TiN has been one of the first coating materials used in the cutting tools industry since 1970's. It is moreover used as diffusion barriers in semiconductor devices and decorative coatings because of its goldish color. The material can be deposited as hard or protective coating by using PVD or CVD techniques.

Zirconium nitride $(\mathrm{ZrN})$ is a hard material similar to TiN with cubic B1 crystal structure and has lattice parameter $\mathrm{a}=4.58 \AA[18]$, which is larger than that of TiN and AlN. ZrN grown by PVD shows a light gold color slightly brighter than TiN. ZrN has similar mechanical properties as TiN but exhibits lower friction coefficient [19, 20]. The hardness of arc-evaporated $\mathrm{ZrN}$ is 21-27 GPa [21, 22].

Hafnium nitride (HfN) has cubic B1 crystal structure with a lattice parameter $\mathrm{a}=4.53 \AA$ [23]. Compared to other elements in the transition metal nitride family, HfN has the highest melting point $\left(T_{m}=3300^{\circ} \mathrm{C}\right)$, largest negative heat of formation and highest elastic moduli $[24,25]$. It can be used as a good coating material for cutting tools and has been recently attracted attention as a buffer layer to enable epitaxial growth of $\mathrm{GaN}$ on $\mathrm{Si}[26,27]$ and as a back contact to enhance light extraction from optical devices [28].

Vanadium nitride (VN) crystallizes with the cubic B1 crystal structure with lattice parameter $\mathrm{a}=4.14 \AA[29]$ and belongs to the class of refractory-metal compounds. The $\mathrm{V}_{2} \mathrm{~N}$ phase with hexagonal structure can be formed along with VN during nitriding. VN has recently drawn intense interest due to the strongly enhanced spin susceptibility when its composition approaches stoichiometry [30]. $\mathrm{VN}$ is also a promising electrode material for electrochemical supercapacitors [31, $32]$.

The equilibrium phase of niobium nitride is the hexagonal $\mathrm{Nb}_{2} \mathrm{~N}$ structure. With thin film deposition approaches it is possible to synthesize the metastable 
(a)

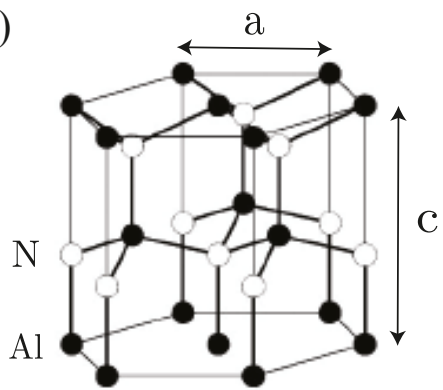

(b)

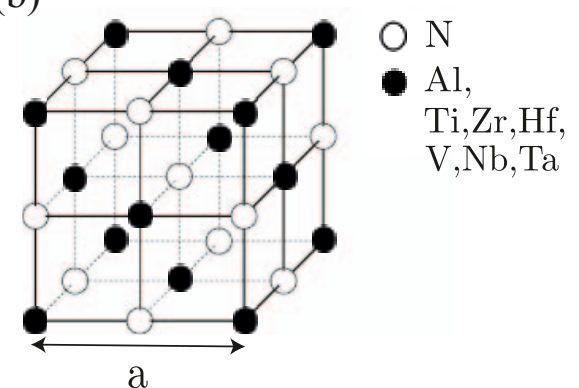

Figure 2.2. (a)The wurtzite structure (B4) (b)The rock-salt ( $\mathrm{NaCl}$ ) structure (B1)

$\mathrm{B} 1$ cubic $\mathrm{NbN}$ at room temperature [33]. The lattice parameter of cubic B1 NbN is $4.39 \AA$ [34]. The as-deposited film shows a hardness of $42 \mathrm{GPa}$ [33] and even at room temperature, $\mathrm{NbN}$ has higher hardness than TiN which makes it promising for protective coating application. Furthermore, it is a material candidate for tunnel junction electrode due to its thermal cyclability and large superconducting energy gap [35].

Tantalium nitride has two phases, the $\mathrm{Ta}_{2} \mathrm{~N}$ with hexagonal structure and the TaN with cubic B1 structure, the lattice parameter of B1 cubic TaN is $4.36 \AA$ [36]. TaN has been used effectively in semiconductor industry because of high melting point and good resistivity. Recently it is utilized as diffusion barrier layers for $\mathrm{Cu}$ wiring of Si semiconductor devices due to the excellent thermal stability [37]. It is also applied as high-speed thermal printing head [38] and thin film resistors [39]. At $0 \mathrm{~K}, \mathrm{VN}, \mathrm{NbN}$ and TaN with cubic B1 structure are dynamical instable [40].

\subsection{Ternary pseudo-binary nitride alloys}

Figure 2.3 shows the ab-initio calculated 0 Kelvin isostructural mixing enthalpies of different ternary nitride alloys as a function of the AlN content. Positive energy of mixing value means that the solid solution is unstable at 0 Kelvin with respect to the reference binary materials and the solid solution will decompose. Despite this instability the alloys can be deposited in a metastable form using low temperature thin film deposition techniques. Higher energy of mixing value indicates higher "thermodynamic" tendency towards decomposition. According to the figure, one says that all the shown binary nitride solid solutions are unstable. Compared to $\mathrm{Ti}_{1-x} \mathrm{Al}_{x} \mathrm{~N}, \mathrm{Zr}_{1-x} \mathrm{Al}_{x} \mathrm{~N}$ and $\mathrm{Hf}_{1-x} \mathrm{Al}_{x} \mathrm{~N}$ have rather higher mixing enthalpies, which means that mixing $\mathrm{HfN}$ and $\mathrm{ZrN}$ with $\mathrm{AlN}$ is exceptionally difficult. $\mathrm{Nb}_{1-x} \mathrm{Al}_{x} \mathrm{~N}$ shows similar values of the mixing enthalpy as $\mathrm{Ti}_{1-x} \mathrm{Al}_{x} \mathrm{~N}$. $\mathrm{Ta}_{1-x} \mathrm{Al}_{x} \mathrm{~N}$ shows the lowest mixing enthalpy.

Ti-Al-N system is a well-established protective coating of cutting tools because of the excellent mechanical properties and oxidation resistance at elevated 


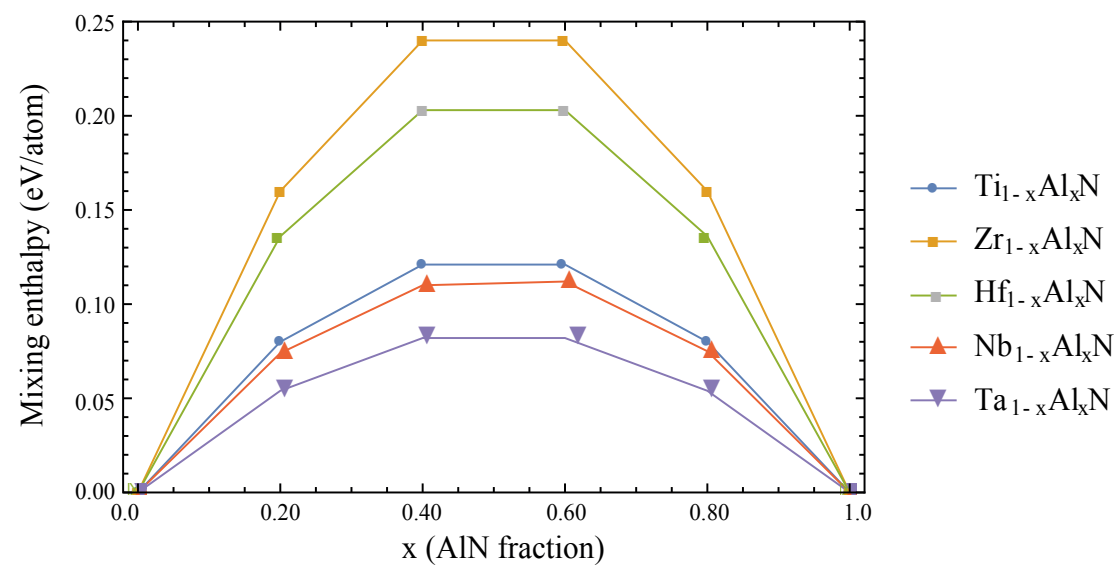

Figure 2.3. Calculated isostructural mixing enthalpy for cubic $\mathrm{B} 1 \mathrm{Ti}_{1-x} \mathrm{Al}_{x} \mathrm{~N}$, $\mathrm{Zr}_{1-x} \mathrm{Al}_{x} \mathrm{~N}, \mathrm{Hf}_{1-x} \mathrm{Al}_{x} \mathrm{~N}, \mathrm{Nb}_{1-x} \mathrm{Al}_{x} \mathrm{~N}$ and $\mathrm{Ta}_{1-x} \mathrm{Al}_{x} \mathrm{~N}$. The data is from Journal of Applied Physics 113, 113510 (2013).

temperatures [41, 42]. Cubic solid solution of Ti-Al-N can be deposited by PVD techniques with $\mathrm{Al}$ content up to 70 atomic \%. At higher $\mathrm{Al}$ contents the hexagonal (wurtzite) phase becomes thermodynamicaly stable [5, 43, 44]. As long as the metastable cubic structure can be maintained, the mechanical properties and the oxidation resistance increase with the $\mathrm{Al}$ content. At elevated temperatures the metastable cubic Ti-Al-N phase decomposes coherently into strained c-TiN and c-AlN enriched domains $[45,46]$. The step is understood as an iso-structural spinodal decomposition [47] and explained by thermodynamic calculations through the observed miscibility gap and the negative second derivative of Gibbs free energy (see Chapter 4) [48-50]. Age hardening of the coating has also been reported and attributed to the coherent spinodal decomposition [3, 45, 47, 51]. Hörling et al. [47] found that the addition of $\mathrm{Al}$ increases the tool's life time however at higher $\mathrm{Al}$ content, the appearing thermodynamically stable wurtzite phase of AlN makes the life time drastically shorter, which correlates with the materials decreased hardness, shown in Figure 1.1. Therefore, controlling the formation of the wurtzite phase of AlN has been the main research focus on the development of Ti-Al-N coatings.

Zr-Al-N system is a highly immiscible material system with the highest mixing enthalpy among the ternary transition metal aluminum nitrides, see Figure 2.3. The large lattice mismatch between c-ZrN and c-AlN (see Table 2.1) has been used to explain the fact that smaller (max. 40\%) amount of c-AlN can be solved in the cubic Zr-Al-N system [52-54]. When the Al content is high $(x>0.70)$, the wurtzite hexagonal structure is stable. For intermediate $\mathrm{Al}$ contents, the structure is a mixture of cubic, hexagonal nano-crystallites and amorphous regions [54-56]. Zr-Al-N coatings with 36 at. $\% \mathrm{Al}$ was shown to form self-organized semi-coherent nanostructures at $900{ }^{\circ} \mathrm{C}[57]$. 
In $\mathrm{Hf}_{1-x} \mathrm{Al}_{x} \mathrm{~N}$, the spinodal decomposition has recently been observed in experiments [25]. The chemical driving force for the isostructural decomposition into binary cubic nitrides is high since the mixing enthalpy is almost twice as big as in $\mathrm{Ti}_{1-x} \mathrm{Al}_{x} \mathrm{~N}$, see Figure $2.3[58,59]$. The maximum amount of AlN soluble in $\mathrm{Hf}_{1-x} \mathrm{Al}_{x} \mathrm{~N}$ is reported to be $x \approx 0.5[25,60,61]$. From $\mathrm{X}$-ray diffraction patterns, it is found that the cubic phase is maintained up to $x=0.33$, then an amorphous or nanocrystalline material is obtained between $x=0.38$ and 0.71 , while from $x=0.77$ wurtzite single phase field is formed [59]. Alloying HfN with AlN gives rise to an increased hardness caused by nanostructured compositional modulations as a result of the onset of spinodal decomposition [25].

Few publications have been dedicated to $\mathrm{V}_{1-x} \mathrm{Al}_{x} \mathrm{~N}, \mathrm{Nb}_{1-x} \mathrm{Al}_{x} \mathrm{~N}, \mathrm{Ta}_{1-x} \mathrm{Al}_{x} \mathrm{~N}$ coatings and solid solutions. $\mathrm{V}_{1-x} \mathrm{Al}_{x} \mathrm{~N}$ coatings have shown excellent mechanical properties, such as high hardness (up to $35 \mathrm{GPa}$ ) and good adhesion to the steel substrates [62]. $\mathrm{V}_{0.48} \mathrm{Al}_{0.52} \mathrm{~N}$ coating was even found superhard ( $>$ 40GPa) [63]. Whereas, spinodal decomposition in $\mathrm{V}_{1-x} \mathrm{Al}_{x} \mathrm{~N}$ is not indicated, which may be related to the lower mixing enthalpy of $\mathrm{V}_{1-x} \mathrm{Al}_{x} \mathrm{~N}$, decomposition by nucleation and growth is observed [64]. The maximum amount of AlN soluble in $\mathrm{V}_{1-x} \mathrm{Al}_{x} \mathrm{~N}$ is observed as $x=0.62$, and below it stabilizes in the metastable B1 structure [63]. A variety of crystallographic phases can be formed for $\mathrm{NbN}$, see section 2.1, which means a higher complexity for investigating solubility in $\mathrm{Nb}_{1-x} \mathrm{Al}_{x} \mathrm{~N}$. The cubic B1 structure was confirmed by experiments [65-68]. It was shown that $\mathrm{B} 1 \mathrm{NbN}$ could be retained up to an $\mathrm{Al}$ concentration of $x=0.45-0.56$ by cathodic arc-evaporation [68] and $x \approx 0.6$ by reactive sputtering [65]. Ab-initio calculations revealed that the B1 structure is (thermodynamically) stable in the composition range $x \approx 0.14-0.7$, and the wurtzite phase is favored at $x>0.7$ [69]. $\mathrm{Nb}_{0.73} \mathrm{Al}_{0.27} \mathrm{~N}$ has shown a maximum hardness value $33.5 \mathrm{GPa}$ [68]. Concerning $\mathrm{Ta}_{1-x} \mathrm{Al}_{x} \mathrm{~N}$ alloys, only $\mathrm{Ta}_{0.89} \mathrm{Al}_{0.11} \mathrm{~N}$ was investigated [70]. It has shown a singlephased cubic B1 solid solution in the as-deposited state, and has been found to be stable until $1100{ }^{\circ} \mathrm{C}$. The measured hardness in the as-deposited state is around 30 GPa.

Pseudo-ternary $\mathrm{Ti}_{1-x} \mathrm{Zr}_{x} \mathrm{~N}, \mathrm{Ti}_{1-x} \mathrm{Hf}_{x} \mathrm{~N}, \mathrm{Ti}_{1-x} \mathrm{~V}_{x} \mathrm{~N}, \mathrm{Ti}_{1-x} \mathrm{Nb}_{x} \mathrm{~N}, \mathrm{Ti}_{1-x} \mathrm{Ta}_{x} \mathrm{~N}$ coatings (no $\mathrm{Al}$ content) have also gained special attention as alternatives for high temperature cutting and machining tools. Generally they have higher hardness than their binary nitride components [71-76]. It has been shown that $\mathrm{Ti}_{1-x} \mathrm{X}_{x} \mathrm{~N}$ $(\mathrm{X}=\mathrm{Zr}, \mathrm{Hf}, \mathrm{V}, \mathrm{Nb}, \mathrm{Ta})$ can form solid solution over the whole $\mathrm{x}$ range $(0<x<1)$ and are thermodynamically stable in the rocksalt structure [77, 78]. $\operatorname{Ti}_{1-x} \mathrm{Zr}_{x} \mathrm{~N}$ has been well studied by experiments and calculations $[72,73,79,80]$. The hardness vales have been found between 32 and $35 \mathrm{GPa}$ for the as-deposited films, while after annealing at $1100-1200{ }^{\circ} \mathrm{C}$ the samples have shown a reduced $24-30$ $\mathrm{GPa}$ hardness [72]. An increase of hardness has been reported with increasing $\mathrm{Zr}$ content [73] and explained by a dominant solid-solution hardening effect [72]. For $\mathrm{Ti}_{1-x} \mathrm{Nb}_{x} \mathrm{~N}$, the material's hardness also increases with increasing $\mathrm{Nb}$ content and a maximum value of $31 \pm 2.4 \mathrm{GPa}$ is found for $\mathrm{x}(\mathrm{Nb})=0.77$ [74]. $\mathrm{Ti}_{1-x} \mathrm{Ta}_{x} \mathrm{~N}$ films have shown to be good conductors with varying density of conduction $[76,81,82]$ and excellent mechanical properties with hardness as high as $42 \mathrm{GPa}$ for $x=0.69$ [76]. 


\subsection{Quaternary nitride alloys}

As summarized in the previous chapter, significant efforts are concentrated on advancing both, the microstructural and compositional design of alloys to achieve higher hardness and extended thermal stability [83]. A novel concept of multicomponent alloying has been established by mixing $\mathrm{CrN}$ and $\operatorname{Ti}_{1-x} \mathrm{Al}_{x} \mathrm{~N}$ [84, 85]. The substantial improvement of thermal stability of quasi-ternary ( $\mathrm{TiCrAl}$ ) N alloys in respect with the characteristic thermal stability of Ti-Al-N, has been explained by the occurence of a novel metastable cubic phase of $\mathrm{Cr}_{1-x} \mathrm{Al}_{x} \mathrm{~N}$. It has extended the increased interest for metastable materials. The $0 \mathrm{~K}$ thermodynamics of quaternary transition metal nitride ( $\mathrm{Ti}-\mathrm{Al}-\mathrm{X}-\mathrm{N}, \mathrm{X}=\mathrm{Zr}, \mathrm{Hf}, \mathrm{V}, \mathrm{Nb}, \mathrm{Ta}$ ) alloys has recently been investigated by Holec using ab initio simulations [86]. Zr improves the oxidation resistance and the as deposited hardness of $\mathrm{Ti}_{1-x} \mathrm{Al}_{x} \mathrm{~N}$ [87, 88]; Hf leads to an inferior oxidation resistance of $\mathrm{Ti}_{1-x} \mathrm{Al}_{x} \mathrm{~N}$ and promotes the formation of cubic domains, however it retards the formation of stable wurtzite AlN during thermal annealing $[89,90]$; The addition of $\mathrm{V}$ to $\mathrm{Ti}_{1-x} \mathrm{Al}_{x} \mathrm{~N}$ hard coatings enables lubricating effects based on oxidation resistance and improves the overall wear resistance [91-93]; $\mathrm{Nb}$ and Ta are also favored due to combining outstanding mechanical properties with good oxidation resistance [94-96].

In paper $\mathrm{V}$ we present a study of the thermal stability as well as structure and stress evolution of cubic $\mathrm{Ti}_{x} \mathrm{Nb}_{y} \mathrm{Al}_{1-x-y} \mathrm{~N}$ coatings during annealing. Paper IV gives a comprehensive overview of the elasticity in cubic quaternary transition metal nitride $\mathrm{Ti}_{x} \mathrm{X}_{y} \mathrm{Al}_{1-x-y} \mathrm{~N}$ alloys where $\mathrm{X}$ is $\mathrm{Zr}, \mathrm{Hf}, \mathrm{V}, \mathrm{Nb}$ or Ta and analyzes the possible multicomponent alloying strategies to engineer the strength and ductility of quaternary solid solution.

\subsection{Multilayers}

Materials can be repeatedly deposited on top of each other to compose nanoscale multilayer structures. Coherent, semi- and incoherent interfaces can be formed and thermodynamic stabilization can be observed. The concept of forming coherent multilayers is offered as an alternative to extend the wear resistance and hardness of monolithic bulk materials [3]. Therefore multilayer coatings have rised the interest of cutting tool industry in the beginning of 1980's.

The altered thermodynamics of $\mathrm{Ti}_{1-x} \mathrm{Al}_{x} \mathrm{~N}$ in the form of $\mathrm{Ti}_{1-x} \mathrm{Al}_{x} \mathrm{~N} / \mathrm{TiN}$ superlattice has been investigated experimentally [3, 15, 97]. Through electron microscopy and atom probe tomography combined with phase field simulations, the occurence of surface directed spinodal decomposition [98] has been shown. In our work the study of multilayers is motivated by the approximation that during the coherent spinodal decomposition of the alloys, the microstruture can locally be described as coherent multilayers with different interfacial orientations. Paper II discusses the mixing thermodynamics of cubic (B1) $\mathrm{Ti}_{1-x} \mathrm{Al}_{x} \mathrm{~N} / \mathrm{TiN}(001)$ multilayers and shows that interfacial effects suppress the mixing enthalpy of $\mathrm{Ti}_{1-x} \mathrm{Al}_{x} \mathrm{~N}$ compared to the monolithic case, suggesting that the multilayer structure has a stabilization effect. Furthermore, Paper III with experiments and $a b$ initio calculations demonstrate that forming semicoherent interfaces during film growth 
might offer higher thermal stability. Paper IV predicts the Young's modulus of the quaternary transition metal nitride multilayers with the [001] and [111] interfacial direction and reveals the materials local Young's modulus distribution affects the microstructure evolution which indicates an effect on the hardness of the materials. 
CHAPTER 3

\section{Structure modeling of alloys}

\subsection{Configurational disorder in alloys}

The degree of disorder in alloys influences the thermodynamic properties of the alloys to a great extent. The translational symmetry of the lattice results in pure elements and ordered compounds that an unit cell is sufficient to simulate material's properties. Long-range ordering in a single crystal can be observed by X-ray diffraction technique to obtain the pair correlation function, see Figure 3.1 (a). The arrangement of atoms is regularly repeated at any distance from an atom. This results in the periodically repeated peaks in the pair correlation function in Figure 3.1 (a). In alloys the configurational disorder breaks this regularity in pair correlation function, only short range order is observed with highly broaden peaks, see Figure 3.1 (b). Repeated supercells of the underlying lattice symmetry in each direction can be used to simulate the disorder in alloys. A sufficiently large structure on which the atoms can be appropriately distributed is needed, thereafter supercells can be used for disordered alloys, impurities, defects and even treating interfacial boundary effects.

In my work two of the most successful modeling disordered alloys approaches were used. One is the construction of "special quasirandom structures" (SQS) [99] by the principle of close reproduction of the perfectly random network for the first few shells around each site. It is an elegant technique with the advantage of an access to atomic forces. Its drawback is the extra computational costs. The second one is based on creating an effective medium that describes the analytical averaging over the disordered configurations. The Coherent Potential Approximation (CPA) [100] is an improved scheme for creating the effective medium, it provides the same scattering properties of the one-component effective medium as the average of alloy components, embedded in this effective medium. 


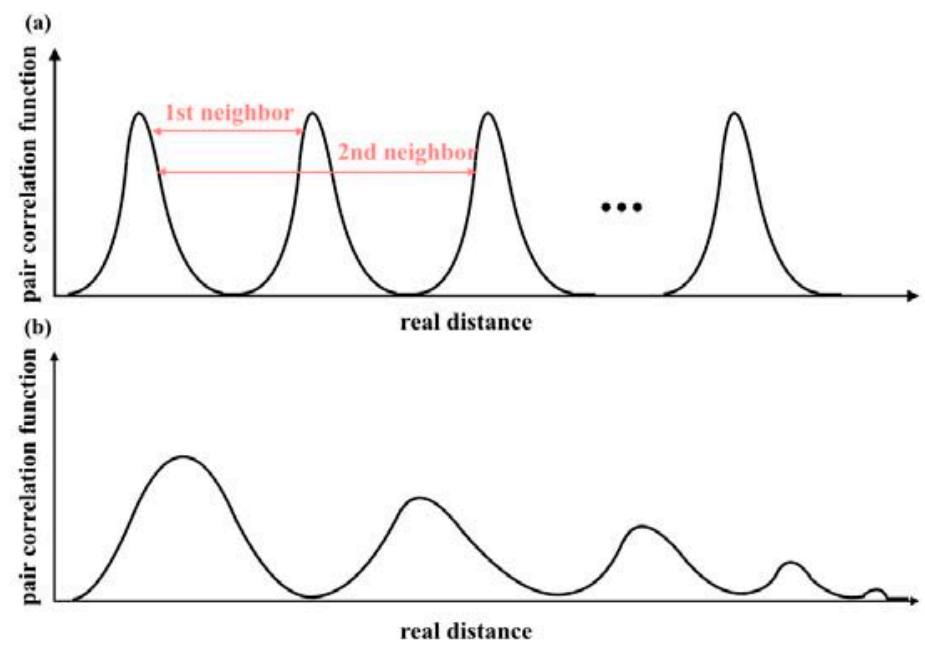

Figure 3.1. Illustration of pair correlation function of (a) Single crystals (b) Alloys.

\subsection{The special quasi-random structure (SQS) ap- proach}

The special quasirandom structure (SQS) approach as suggested by Zunger et al [99] is introduced for a binary $\mathrm{A}_{1-x} \mathrm{~B}_{x}$ solid solutions. During the SQS algorithm one uses spin variables $\sigma_{i}$ to describe the atomic occupation, if the $i$ th site is occupied by atom $\mathrm{A}, \sigma_{i}$ is +1 , otherwise it equals -1 . The atomic configuration of an alloy with $N$ sites can be given by the vector $\sigma=\left\{\sigma_{1}, \sigma_{2}, \ldots, \sigma_{N}\right\}$. Then one can define a characteristic function $\Phi_{f}^{(n)}(\sigma)$ for a given n-site in clusters $f$ by the product of the spin variables of $f$ :

$$
\Phi_{f}^{(n)}(\sigma)=\prod_{i \in f} \sigma_{i}
$$

These functions form a complete and orthonormal set, with the inner product between two functions:

$$
\left\langle\Phi_{f}^{(n)}(\sigma), \Phi_{g}^{(n)}(\sigma)\right\rangle=\frac{1}{2^{N}} \sum_{\sigma} \Phi_{f}^{(n)}(\sigma) \Phi_{g}^{(n)}(\sigma)=\delta_{f, g} .
$$

where the sum runs over all the atomic configurations on the $\mathrm{N}$ sites. The function equals to 1 only if two clusters are the same in the crystal, otherwise it is 0 . This means that one can expand any function of configuration in this basis set:

$$
F(\sigma)=\sum_{f} F_{f}^{(n)} \Phi_{f}^{(n)}(\sigma) .
$$


The expansion coefficients are

$$
F_{f}^{(n)}=\left\langle F(\sigma), \Phi_{f}^{(n)}(\sigma)\right\rangle .
$$

As for the total energy of an alloy, the expansion coefficients are so-called effective cluster interactions (ECI), given by

$$
V_{f}^{(n)}=\left\langle E_{t o t}(\sigma), \Phi_{f}^{(n)}(\sigma)\right\rangle .
$$

The total energy of an alloy can then be calculated with arbitrary configuration, given by

$$
E_{t o t}=\sum_{f} V_{f}^{(n)} \xi_{f}^{(n)} .
$$

where $\xi_{f}^{(n)}$ is the $n$-site correlation function for the cluster $f$, defined as the average value of the symmetrically identical characteristic function, $\xi_{f}^{(n)}=\left\langle\Phi_{f}^{(n)}\right\rangle$.

In the case of a completely random alloy, $\xi_{f}^{(n)}$ equals to zero and can be expressed with the help of the Warren-Cowlley short range order (SRO) parameters [101]. For a binary $\mathrm{A}_{1-x} \mathrm{~B}_{x}$ alloy, the SRO parameters of $\mathrm{A}$ and $\mathrm{B}$ atoms within a sublattice can be optimized towards a random distribution of $\mathrm{A}$ and $\mathrm{B}$ that they are close to zero for as many coordination shells as possible. Due to the limitation of the supercell size, it is not practically possible to obtain zero value of the SRO parameters for all coordination shells, $E_{\text {tot }}$ could affect predictions of some properties. For example, the total energy needs to be converged with respect to the supercell size [102] and therefore the accuracy of using the SQS method must be weighed against the computational cost. With today's supercomputers, SQS approach can excellently reproduce the total energy of a random alloy. However, there are still limitations. One of the limitations is modeling tensorial properties. The problem with the SQS approach is that it breaks inherently the point symmetry of the underlying crystal lattice. Thus the tensorial properties can differ from experimental values with the chosen SQS model. A symmetry-based projection technique was introduced $[103,104]$ to extract the closest approximation of the elastic tensor components. This technique was used in Paper IV to derive the elastic properties of transition metal alloys. More details will be shown in Chapter 5. In Paper I, we point out the limitations and methodological corrections for the application of SQS approach in studies of advanced properties of alloys and multilayers.

\subsubsection{Modeling multilayered alloys}

It is shown by Ruban et al [102] that in inhomogeneous systems such as multilayer alloys, the structral SRO parameters should depend on the layer index. The interaction and the large relaxation of the interfacial atoms renormalise the effective cluster interactions(ECI) [102] so that layer dependent cluster expansion has to be applied. Therefore, all properties have to be indexed with the layer number $(\lambda)$ with keeping the homogeneity only in the two periodic directions ( $x$ and $y$ ) [102]. In Paper I and Paper II, We use a composition profile through the interfaces by 


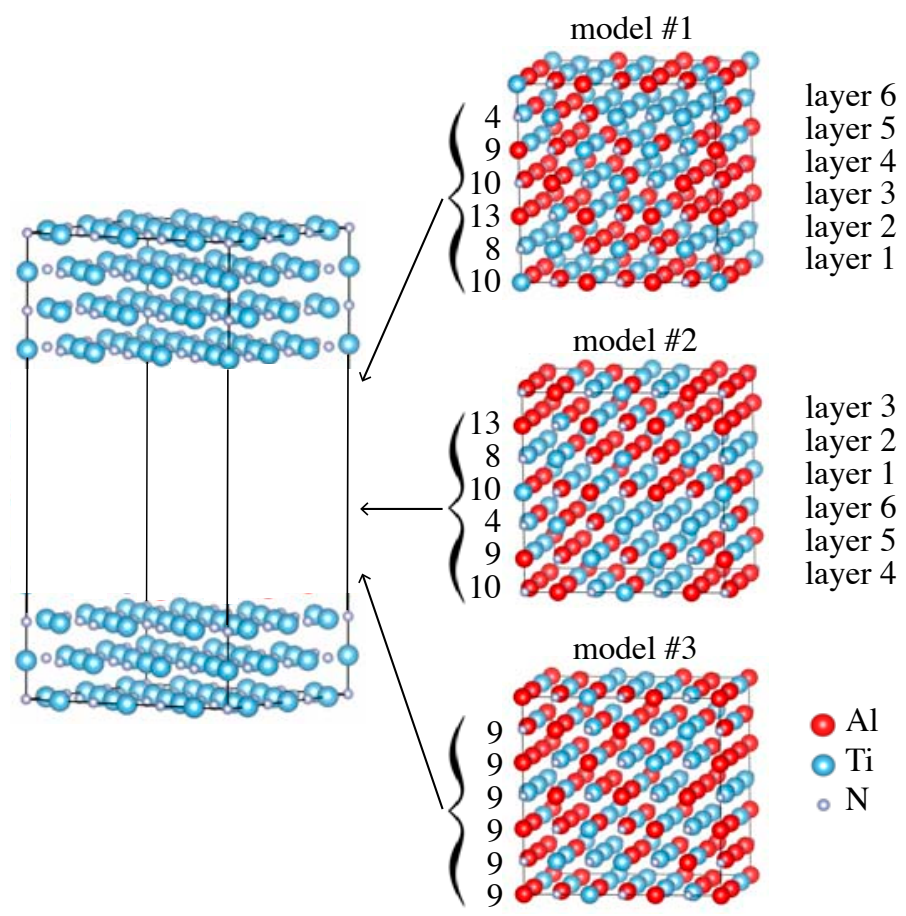

Figure 3.2. Three different bulk SQS models of $\mathrm{Ti}_{0.5} \mathrm{Al}_{0.5} \mathrm{~N}$ to build the multilayer of $\mathrm{TiN} / \mathrm{Ti}_{0.5} \mathrm{Al}_{0.5} \mathrm{~N}$.

keeping the same composition in each layer of the SQS model to obtain results relevant for simulations of disordered multilayers.

The total energy density of the multilayer can be written as

$$
e^{\mathrm{ML}}=\sum_{i} y_{i} e_{i}^{\text {bulk }}+e^{\text {interface }}\left(\left\{y_{i}\right\}\right)+e^{\text {strain }}\left(\left\{y_{i}\right\}\right)
$$

where $y_{i}$ are the content ratios and $e_{i}^{\text {bulk }}$ denote the unstrained bulk energies of the components in the multilayer, $e^{\text {interface }}$ and $e^{\text {strain }}$ stand for the interfacial and constituent strain energies per surface area [105]. The last two terms can strongly depend on the atomic arrangement in a finite size model.

In Paper I, we aim to underline the dependence of the derived mixing enthalpy values on the chosen SQS supercell in the multilayers. We generate three different bulk $\mathrm{Ti}_{0.5} \mathrm{Al}_{0.5} \mathrm{~N}$ with a size of $(3 \times 3 \times 3)$ and sandwiched them between the TiN layers, as shown in Figure 3.2. The model \#1 was created by minimizing the bulk Warren-Cowlley SRO parameters up to the seventh shell without constraining the composition profile. Model \#2 was obtained from model \#1 by a layer shift. The model $\# 3$ has also been created by minimizing the bulk Warren-Cowlley SRO parameters up to the seventh shell but with keeping the same composition $x_{\lambda}=0.5$ in each layer. The derived in-plane SRO parameters of all the three 
Table 3.1. The layer composition $x_{\lambda}$ and the layer Warren-Cowlley SRO parameters of three SQS models.

\begin{tabular}{l|cccccccc}
\hline & $x_{\lambda}$ & 1st & 2nd & 3rd & 4th & 5th & 6 th & 7th \\
\hline & \multicolumn{7}{c}{ model \#1 and \#2 } \\
layer 1 & 0.56 & -0.01 & -0.01 & -0.13 & -0.01 & -0.01 & -0.35 & -0.13 \\
layer 2 & 0.44 & 0.21 & 0.10 & -0.24 & -0.24 & 0.10 & -0.35 & -0.24 \\
layer 3 & 0.72 & 0.17 & -0.11 & -0.11 & -0.11 & -0.11 & -0.38 & -0.11 \\
layer 4 & 0.56 & -0.01 & 0.10 & -0.24 & -0.01 & 0.10 & -0.35 & -0.24 \\
layer 5 & 0.50 & -0.22 & -0.22 & 0.22 & 0.11 & -0.22 & -0.56 & 0.22 \\
layer 6 & 0.22 & 0.20 & -0.13 & -0.13 & -0.13 & -0.13 & -0.29 & -0.13 \\
\hline & & & \multicolumn{7}{c}{ model \#3 } & & & \\
layer 1 & 0.50 & 0.00 & -0.22 & 0.00 & 0.11 & -0.22 & -0.56 & 0.00 \\
layer 2 & 0.50 & 0.00 & 0.00 & -0.22 & 0.00 & 0.00 & -0.11 & -0.22 \\
layer 3 & 0.50 & 0.00 & 0.00 & -0.22 & 0.00 & 0.00 & -0.11 & -0.22 \\
layer 4 & 0.50 & -0.44 & 0.22 & 0.22 & -0.22 & 0.22 & -0.11 & 0.22 \\
layer 5 & 0.50 & 0.11 & 0.22 & -0.22 & -0.22 & 0.22 & -0.56 & -0.22 \\
layer 6 & 0.50 & 0.00 & -0.33 & 0.11 & 0.00 & -0.33 & -0.11 & 0.11 \\
\hline
\end{tabular}

supercells are listed in Table 3.1. The most relevant difference between the three models are the compositions $x_{\lambda}$, especially at the interface with TiN. Model \#3 has the proper constrained value $x_{\lambda}=0.5$ in each layer so that it also represents bulk randomness, which corresponds to the proper treatment of inhomogeneous systems [102].

\subsection{The Coherent Potential Approximation (CPA)}

The concept of effective medium with keeping the translational symmetry of the underlying lattice is designed to average out the disorder. Coherent potential approximation (CPA) makes use of the one-electron Green's function, which is a selfaveraging quantity. The method aims to find a one-component effective medium with a Green's function that has translational symmetry of the underlying lattice. It was originally introduced by Soven [100] for the electronic structure problem and by Taylor [106] to deal with phonons of disordered alloys. The CPA was reformulated with the multiple-scattering theory of Korringa-Kohn-Rostoker (KKR) [107, 108] by Györffy [109], and since then it was widely used. The objective of the CPA is to provide the same scattering properties of the one-component effective medium as the average of alloy components, which is schematically illustrated in Figure 3.3. With the single site approximation, the advantage of CPA against the SQS method is that one does not need to build large supercells to ensure the randomness, therefore disordered alloys can be treated with less demanding calculations. However, the single site character does not take into account other effects such as local environment effects, short and long-range order effects, charge transfer, etc. One has to apply additional models and do extra calculations beyond the CPA calculations. For example, to take into account the effect of charge transfer 


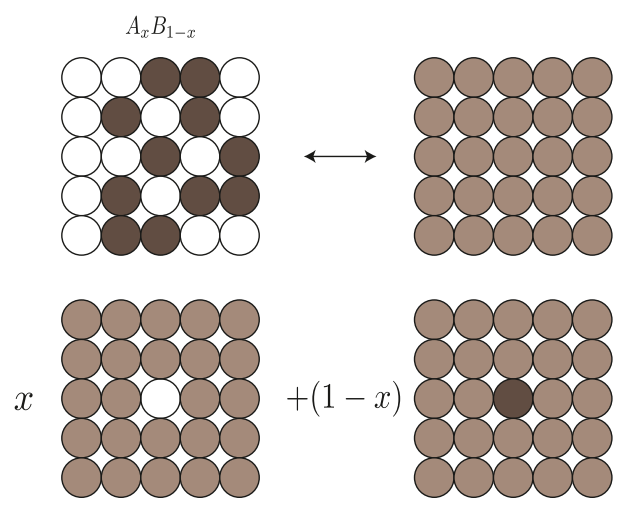

Figure 3.3. Schematic representation of the principle of CPA approximation for a disordered binary alloy $\mathrm{A}_{x} \mathrm{~B}_{1-x}$. See the text for details.

between components, one can use the screened impurity model(SIM), where each atom is treated as an impurity in the effective CPA medium and the net charge is screened by the first coordination shell of the nearest neighbor [110]. To estimate the local relaxations, the effective tetrahedron method (ETM) [111] which considers the effect of a local volume relaxation is proven to work accurate.

In Paper $\mathrm{V}$, we modeled $\mathrm{Ti}_{x} \mathrm{Nb}_{y} \mathrm{Al}_{1-x-y} \mathrm{~N}$ alloy (B1 crystal structure) with four lattice sites in the unit cell, one metal, one nitrogen and two empty spheres were included to improve the space filling in the atomic sphere approximation (ASA) [112]. Through the use of the independent sublattice model (ISM) [50], the additional relaxation effect of the nitrogen and metal atoms relative to each other has been considered and the local relaxation energy was calculated as:

$$
E_{\text {rel }}=E_{\text {tot }}-E_{\text {unrel }}
$$

where $E_{t o t}$ is the total energy of a disordered alloy with fully relaxed ionic positions and $E_{\text {unrel }}$ is the total energy of the same system with the ideal B1 crystal lattice positions. To calculate $E_{\text {rel }}$ one only needs to consider relaxations of nitrogens, because of the shown negligible displacement of the metallic atoms [50]. One can derive an expression for $E_{r e l}$ for $\mathrm{N}$ atoms in $\mathrm{c}-\mathrm{Ti}_{x} \mathrm{Nb}_{y} \mathrm{Al}_{1-x-y} \mathrm{~N}$ as:

$$
E_{r e l}=6\left(\nu_{T i A l} \rho_{T i A l}+\nu_{N b A l} \rho_{N b A l}+\nu_{T i N b} \rho_{T i N b}\right) .
$$

where $\nu_{T i A l}, \nu_{N b A l}$ and $\nu_{T i N b}$ are the relaxation energies and $\rho_{T i A l}, \rho_{N b A l}$ and $\rho_{T i N b}$ are the probabilities of a nitrogen atom being surrounded by the corresponding two metal atoms in one direction. The relaxation energy parameters were determined by supercell calculations with and without atomic relaxations. The supercells were built using the Special Quasirandom Structure (SQS) approach introduced before. The supercell calculations resulted in $\nu_{T i A l}=-0.0321061 \mathrm{eV} /$ atom, $\nu_{N b A l}=-0.116299 \mathrm{eV} /$ atom and $\nu_{T i N b}=-0.010324 \mathrm{eV} /$ atom to the relaxation energies. 


\section{CHAPTER 4}

\section{Mixing thermodynamics and decomposition}

\subsection{Gibbs free energy}

To predict the thermodynamic phase diagram of a binary solid solution, see Figure 4.1, one has to calculate Gibbs free energy. Gibbs free energy $G$, is a thermodynamic potential of system at constant pressure $p$ and temperature $T$ with a constant number of particles.

$$
G(p, T)=E+p V-T S=H-T S=F+p V
$$

where $E$ is the total (internal) energy calculated through electronic structure calculations, $H$ is the enthalpy, $S$ denotes the entropy and $F$ is Helmholtz free energy. When $T=0 \mathrm{~K}$ and $p=0 \mathrm{GPa}, G=E$.

To determine whether a solid solution is thermodynamically stable or not, one has to calculate the Gibbs free energy of mixing $\Delta G$ as,

$$
\Delta G=G_{\text {solution }}-\sum_{i} x_{i} G_{i}
$$

Here $G_{\text {solution }}$ is the Gibbs free energy of the solid solution, $x_{i}$ and $G_{i}$ are the concentration and the Gibbs free energy of the components or reference materials. Moreover, $\Delta G$ is expressed as

$$
\Delta G=\Delta H-T \Delta S
$$

where $\Delta H$ and $\Delta S$ are defined as mixing enthalpy and mixing entropy, respectively. If $\Delta G<0$, the solution is stable with respect to their competing components and will be formed spontaneously. If $\Delta G>0$, then the solution is unstable (or metastable) and phase separation should occur. 
(a)

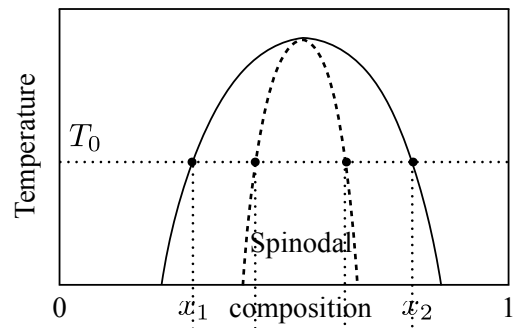

(b)

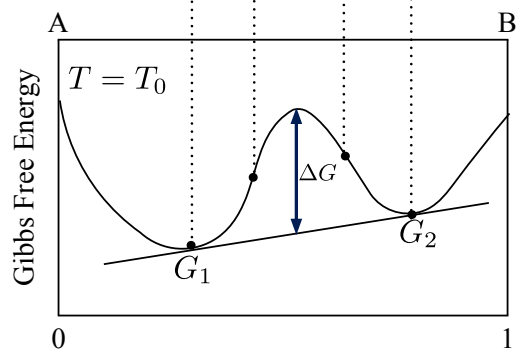

Figure 4.1. Illustration of the phase diagram and the Gibbs free energy curve of a binary alloy. (a) A schematic phase Temperature-compositon $(x)$ diagram of an alloy. The solid line shows the binodal curve, while the dashed one is the spinodal curve. (b) The free energy as a function of composition for the phase separation. Mixing Gibbs free energy $\Delta G$ is minimized by a common tangent construction.

Spinodal decomposition happens if the phase separation occurs spontaneously in the system without nucleation and growth. The range of spinodal decomposition is shown in Figure 4.1(b) and defined as

$$
\frac{\partial^{2} G}{\partial^{2} x}<0
$$

For a multicomponent alloy with more than two components, such as $\mathrm{Ti}_{x} \mathrm{Nb}_{y} \mathrm{Al}_{z} \mathrm{~N}$ in Paper $\mathrm{V}$, the second directional derivative is calculated as

$$
\frac{\partial^{2} G}{\overrightarrow{\Delta R^{2}}}=\frac{G(\mathbf{R}+\overrightarrow{\Delta R})+G(\mathbf{R}-\overrightarrow{\Delta R})-2 G(\mathbf{R})}{\left|\overrightarrow{\Delta R^{2}}\right|} .
$$

In direction $\overrightarrow{\Delta R}=(\Delta x, \Delta y, \Delta z)$ at the composition plane point $\mathbf{R}=(x, y, z)$. Interpolation is used to derive the mixing energy and its second directional derivatives.

\subsection{Mixing enthalpy in multilayers}

In this section, we explain the thermodynamic mixing of $\mathrm{Ti}_{1-x} \mathrm{Al}_{x} \mathrm{~N}$ in the superlattice $\mathrm{Ti}_{1-x} \mathrm{Al}_{x} \mathrm{~N} / \mathrm{TiN}(001)$ in comparison with the one of bulk $\mathrm{Ti}_{1-x} \mathrm{Al}_{x} \mathrm{~N}$. Figure 4.2 shows a schematic way of calculating the coherent phase separation in 
(a)

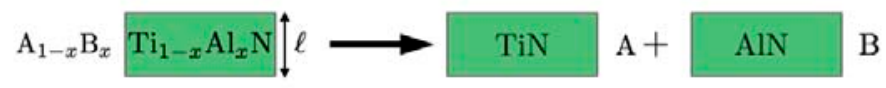

(b)

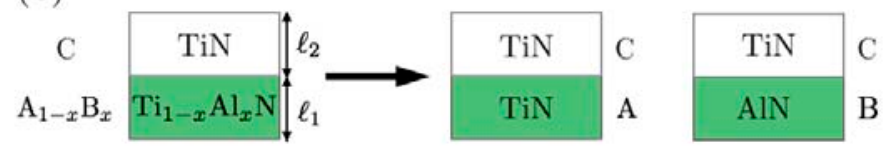

Figure 4.2. Schematic diagram of the phase separation of (a) $\mathrm{Ti}_{1-x} \mathrm{Al}_{x} \mathrm{~N}$ bulk and (b) $\mathrm{Ti}_{1-x} \mathrm{Al}_{x} \mathrm{~N} / \mathrm{TiN}$ multilayer.

cubic $\mathrm{B} 1 \mathrm{Ti}_{1-x} \mathrm{Al}_{x} \mathrm{~N}$ bulk and $\mathrm{Ti}_{1-x} \mathrm{Al}_{x} \mathrm{~N} / \mathrm{TiN}(001)$ multilayer. With using the figure, the mixing enthalpy is written as

$$
\Delta H^{\mathrm{Ti}_{1-x} \mathrm{Al}_{x} \mathrm{~N}}(x)=\frac{1}{N}\left(E_{\ell}^{\mathrm{Ti}_{1-x} \mathrm{Al}_{x} \mathrm{~N}}(x)-(1-x) E_{\ell}^{\mathrm{TiN}}-x E_{\ell}^{\mathrm{AlN} / \mathrm{TiN}}\right),
$$

for bulk $\operatorname{Ti}_{1-x} \mathrm{Al}_{x} \mathrm{~N}$ and

$\Delta H^{\mathrm{Ti}_{1-x} \mathrm{Al}_{x} \mathrm{~N} / \mathrm{TiN}}\left(x, \ell_{1}, \ell_{2}\right)=\frac{1}{N}\left(E_{\ell_{1} / \ell_{2}}^{\mathrm{Ti}_{1} \mathrm{Al}_{x} \mathrm{~N} / \mathrm{TiN}}(x)-(1-x) E_{\ell_{1} / \ell_{2}}^{\mathrm{TiN}}-x E_{\ell_{1} / \ell_{2}}^{\mathrm{AlN} / \mathrm{TiN}}\right)$.

for the multilayer. $N$ is the total number of atoms in the $\operatorname{Ti}_{1-x} \mathrm{Al}_{x} \mathrm{~N}$ slab, $E_{\ell}^{A}$ denotes the equilibrium total energy of material $A$ with $\ell$ layers along the crystallographic (001) direction. If $\Delta H$ is positive, $\operatorname{Ti}_{1-x} \mathrm{Al}_{x} \mathrm{~N}$ will decompose to TiN and AlN and if it is negative, the structure is stable.

For the $\mathrm{Ti}_{1-x} \mathrm{Al}_{x} \mathrm{~N} / \mathrm{TiN}(001)$ multilayer, the end components are pure TiN and AlN/TiN(001). The mixing enthalpy $\Delta H^{\mathrm{Ti}_{1-x} \mathrm{Al}{ }_{x} \mathrm{~N} / \mathrm{TiN}}$ can be further divided into two terms: (i) the in-plane lattice matching or strain effects and (ii) the remaining so called chemical interaction of $\mathrm{Ti}_{1-x} \mathrm{Al}_{x} \mathrm{~N}$ and TiN through the (001) interface.

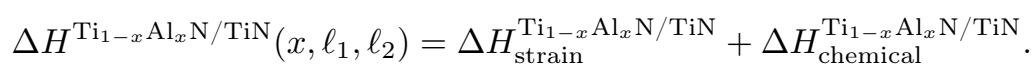

To quantify the effect of strain on the mixing enthalpy, two methods are presented and compared in this thesis. The first approach is the constituent strain method proposed by Ozolinšs et al [105]. The constituent strain energy $E_{\text {const }}^{\mathrm{AB} / \mathrm{C}}$ in $\mathrm{AB} / \mathrm{C}$ multilayer is defined by

$$
E_{\text {const }}^{\mathrm{AB} / \mathrm{C}}=\min _{a}\left[y \Delta E^{\mathrm{AB}}(a)+(1-y) \Delta E^{\mathrm{C}}(a)\right] .
$$

Here, $y=\ell_{1} /\left(\ell_{1}+\ell_{2}\right)$ denotes the relative thickness of the AB layer and

$$
\Delta E^{\alpha}(a)=\min _{c} E^{\alpha}(a, c)-E_{0}^{\alpha},
$$



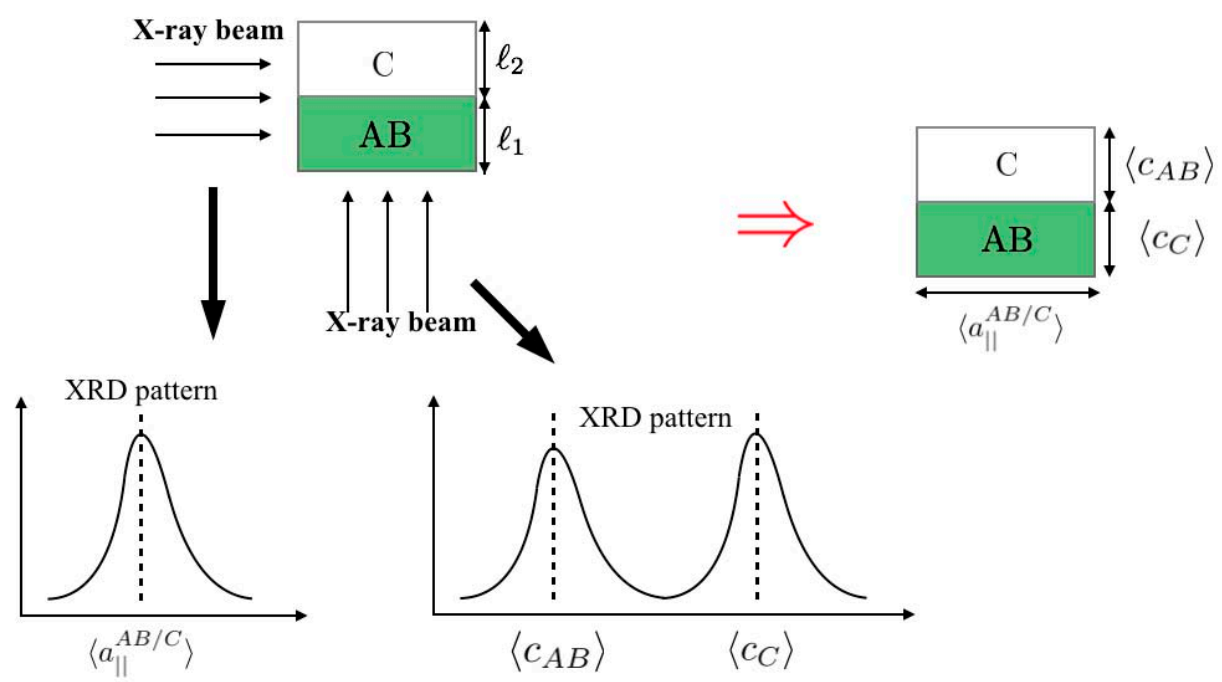

Figure 4.3. Schematic drawing of experimental way of obtaining structural data.

stands for the epitaxial strain energy, $a$ and $c$ denote the in-plane and out-ofplane lattice parameters and $E_{0}^{\alpha}$ is the equilibrium energy of layer $\alpha$. Using $E_{0}^{\alpha}$ from Eq.(4.10) and substituting it into Eq.(4.9) one obtains $E_{\text {const }}$ for each system. Further with the help of Eq.(4.7), the constituent strain contribution to the mixing enthalpy can be derived as:

$$
\begin{aligned}
& \Delta H_{\mathrm{const}}^{\mathrm{AB} / \mathrm{C}}\left(x, \ell_{1}, \ell_{2}\right)=\frac{1}{N}( \\
& \min _{a}\left[y \bar{E}_{\ell_{1} / \ell_{2}}^{\mathrm{AB}}(a)+(1-y) \bar{E}_{\ell_{1} / \ell_{2}}^{\mathrm{C}}(a)\right]- \\
& (1-x) \min _{a}\left[y \bar{E}_{\ell_{1} / \ell_{2}}^{\mathrm{A}}(a)+(1-y) \bar{E}_{\ell_{1} / \ell_{2}}^{\mathrm{C}}(a)\right]- \\
& \left.x \min _{a}\left[y \bar{E}_{\ell_{1} / \ell_{2}}^{\mathrm{B}}(a)+(1-y) \bar{E}_{\ell_{1} / \ell_{2}}^{\mathrm{C}}(a)\right]\right) .
\end{aligned}
$$

and the remaining contributions come from the interface chemistry.

Another way of making the energy partitioning into a strain and chemical contributions implements the experimentally available structural data of the multilayers. It is based on the coherent in-plane lattice parameter of the full system and the averaged inter-layer distances along the [001] growth direction. Therefore, we call this method coherency strain approach. According to Figure 4.3, in an $\mathrm{AB} / \mathrm{C}$ multilayer one assumes two strong diffraction peaks in the growth direction what correspond to the interlayer distance in material $\mathrm{AB}$ and $\mathrm{C}$, respectively. Therefore one can introduce an energy expression

$$
\mathcal{E}_{\ell_{1}+\ell_{2}}^{\mathrm{AB} / \mathrm{C}}(x)=y E_{\ell_{1}+\ell_{2}}^{\mathrm{AB}}\left(x, a_{\|}^{\mathrm{AB} / \mathrm{C}},\left\langle c_{\mathrm{AB}}\right\rangle\right)+(1-y) E_{\ell_{1}+\ell_{2}}^{\mathrm{C}}\left(a_{\|}^{\mathrm{AB} / \mathrm{C}},\left\langle c_{\mathrm{C}}\right\rangle\right),
$$




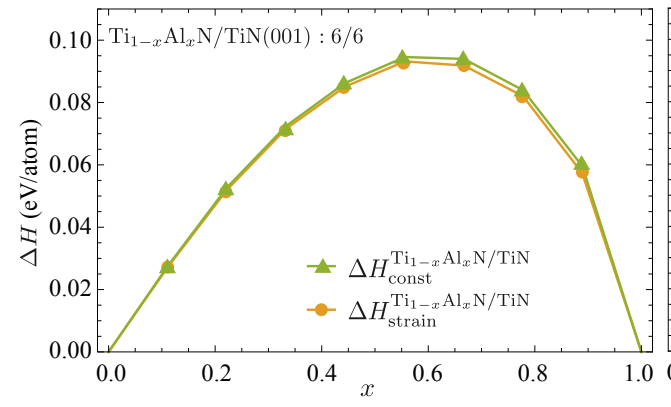

(a)

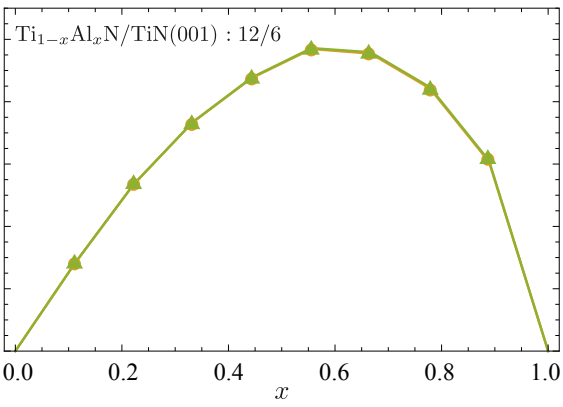

(b)

Figure 4.4. The mixing enthalpy with the constituent strain and coherency strain effect of (a)6 layers $\mathrm{Ti}_{1-x} \mathrm{Al}_{x} \mathrm{~N} / 6$ layers $\mathrm{TiN}$ multilayer (b)12 layers $\mathrm{Ti}_{1-x} \mathrm{Al}_{x} \mathrm{~N} / 6$ layers $\mathrm{TiN}$ multilayer.

where $a_{\|}^{\mathrm{AB} / \mathrm{C}}$ is the coherent in-plane lattice parameter and $\left\langle c^{\mathrm{AB}}\right\rangle,\left\langle c^{\mathrm{C}}\right\rangle$ are the averaged out-of-plane lattice parameters. Then, the strain contribution in the mixing enthalpy is defined as

$$
\Delta H_{\text {strain }}^{\mathrm{AB} / \mathrm{C}}=\frac{1}{N}\left(\mathcal{E}_{\ell_{1} / \ell_{2}}^{\mathrm{AB} / \mathrm{C}}(x)-(1-x) \mathcal{E}_{\ell_{1} / \ell_{2}}^{\mathrm{A} / \mathrm{C}}-x \mathcal{E}_{\ell_{1} / \ell_{2}}^{\mathrm{B} / \mathrm{C}}\right) .
$$

This expression might reflect the meaning of strain contribution in experimental studies.

The calculated mixing enthalpy values of both methods are shown in Figure 4.4. One sees that the coherency strain contribution agrees well with the constituent strain contribution. Though, in the coherency strain method one includes certain chemical effect through the interface, by the coherent lattice parameter, the contribution is negligible. In Paper II, we base our description on the concept of coherency strain rather than the constituent one because it allows us to connect the results of the simulations to an experimental interpretation. More details about the comparison of mixing enthalpy of $\mathrm{Ti}_{1-x} \mathrm{Al}_{x} \mathrm{~N}$ bulk and $\mathrm{Ti}_{1-x} \mathrm{Al}_{x} \mathrm{~N} / \mathrm{TiN}$ multilayers are presented in Chapter 7.

\subsection{Gibbs free energy calculated with the Debye model}

At finite temperature, the Gibbs free energy $G$ is written as

$$
G(p, T)=F_{\text {chemical }}+F_{v i b}+F_{\text {mag }}+p V,
$$

using the Helmholtz free energy $F$

$$
F=E_{\text {chemical }}+E_{v i b}+E_{m a g}-T\left(S_{\text {chemical }}+S_{v i b}+S_{m a g}\right) .
$$




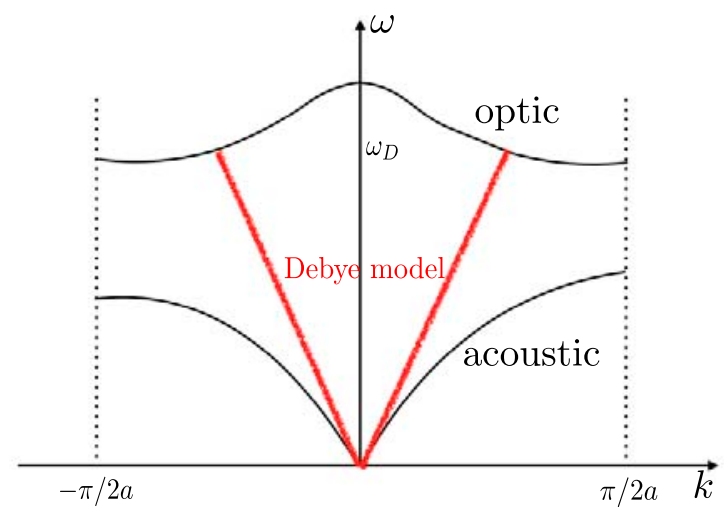

Figure 4.5. The Debye approximation to the dispersion relation. The upper branch is called the optical and the lower branch is the acoustic.

The total energy $E_{\text {chemical }}$ is calculated using Density Functional Theory (DFT), see Chapter 6 . The material systems discussed in this thesis are non-magnetic and therefore, the magnetic contribution is neglected.

For a completely random disordered solid solution, the configurational entropy $S_{\text {conf }}$ is calculated using the mean field approximation,

$$
S_{\text {conf }}=-k_{B} \sum_{i} x_{i} \ln \left(x_{i}\right)
$$

where $k_{B}$ is Boltzmann's constant and $x_{i}$ is the concentration of $i$ th type atoms. $S_{\text {conf }}$ is temperature independent.

In this thesis, the vibrational energy and entropy is approximated using the Debye model. The model is explained in Figure 4.5. It treats the atomic vibrations of the lattice with a linear dispersion relation $\omega=c k$ and deals only with the acoustic branches. The Debye temperature $\theta_{D}$ can be related to the maximum frequency $\omega_{D}$,

$$
k_{B} \theta_{D}=\hbar \omega_{D},
$$

The average sound velocity, $\bar{s}$, can be defined by Christoffel equation [113] for sound velocities as

$$
\frac{3}{\bar{s}^{3}}=\sum_{\lambda} \int \frac{1}{s_{\lambda}^{3}(\Omega)} \frac{d \Omega}{4 \pi} .
$$

where $s_{\lambda}(\Omega)$ is the phase velocity of the long wavelength acoustic phonons and the integral means an average over the propagation direction. If $\bar{s}$ is isotropic, for the longitudinal (L) and the two degenerate transverse $(\mathrm{T})$ branches, then

$$
\frac{3}{\bar{s}_{i c}^{3}}=\frac{1}{s_{L}^{3}}+\frac{2}{s_{T}^{3}} .
$$


here $s_{L}$ and $s_{T}$ are related with the elastic constants and the mass density $\rho$,

$$
\begin{aligned}
& s_{L}=\sqrt{\left[C_{11}+\frac{2}{5}\left(2 C_{44}+C_{12}-C_{11}\right)\right] / \rho}, \\
& s_{T}=\sqrt{\left[C_{44}-\frac{1}{5}\left(2 C_{44}+C_{12}-C_{11}\right)\right] / \rho},
\end{aligned}
$$

The Debye temperature $\theta_{D}$ can be expressed as

$$
\theta_{D}=\frac{\hbar}{k_{B}}(6 \pi N / V)^{1 / 3} \bar{s}_{i c}=\frac{\hbar}{k_{B}}(6 \pi N \rho / M)^{1 / 3} \bar{s}_{i c},
$$

$M$ is the mass of a mole of the material. Then at temperature $T$, one calculates the vibrational energy and entropy as

$$
\begin{aligned}
& E_{v i b}(T)=\frac{9}{8} N \hbar \omega_{D}+\frac{9 N \hbar}{\omega_{D}^{3}} \int_{0}^{\omega_{D}} \frac{\omega^{3}}{\exp \left(\hbar \omega / k_{B} T\right)-1} d \omega \\
& S_{v i b}(T)=\frac{12 N k_{B}}{\omega_{D}^{3}} \int_{0}^{\omega_{D}} \frac{\hbar \omega^{3} /\left(k_{B} T\right) d \omega}{\exp \left(\hbar \omega / k_{B} T\right)-1}-3 N k_{B} \ln \left[1-\exp \left(-\hbar \omega_{D} / k_{B} T\right)\right]
\end{aligned}
$$

Substituting these expressions into equation (4.14) and (4.15), the Gibbs free energy with the vibration contribution can be obtained. In Paper $\mathrm{V}$, we investigate the mixing Gibbs free energy of $\mathrm{Ti}_{x} \mathrm{Nb}_{y} \mathrm{Al}_{1-x-y} \mathrm{~N}$ at usual cutting operation temperature.

\subsection{Thermal expansion coefficient (TEC)}

The linear thermal expansion coefficient (TEC) is calculated as

$$
\alpha(T)=\sum_{r} \frac{1}{3 B}\left(\frac{\partial S_{r}}{\partial V}\right)_{T} .
$$

where $T$ is the temperature, $B$ is the isothermal bulk modulus, $S_{r}$ stands for the different entropy contributions and $V$ denotes the volume. The volume dependence of each entropy term can be written with the help of the Grüneisen parameter $\gamma_{r}$ and the heat capacity at constant volume $\left(C_{V}\right)_{r}$. Considering electronic (el.) and phononic (phon.) entropies one has

$$
\alpha(T)=\frac{\gamma_{\mathrm{el} .}\left(C_{V}\right)_{\mathrm{el} .}}{3 B V}+\frac{\gamma_{\mathrm{phon} .}\left(C_{V}\right)_{\mathrm{phon}} .}{3 B V} .
$$

The heat capacity which is the ratio of the heat added or removed within the temperature change, are approximated through the Debye model as

$$
\begin{array}{r}
\left(C_{V}\right)_{\text {phon. }}(T)=9 N k_{B}\left(\frac{T}{\theta_{D}}\right) \int_{0}^{3} \frac{x^{4} e^{\theta_{D} / T} p^{x}}{\left(e x p^{x}-1\right)^{2}} d x \\
\left(C_{V}\right)_{\text {el. }}(T)=\frac{2 \pi^{2}}{3} k_{B}^{2} T \times \operatorname{DOS}\left(\epsilon_{F}\right) .
\end{array}
$$


Then the thermal expansion coefficients that describes how the materials volume is altered by expansion with a change in temperature can be approximated. In Paper VI, the thermal expansion coefficients of $\mathrm{Ti}_{1-x-y} \mathrm{X}_{y} \mathrm{Al}_{x} \mathrm{~N}$ (X=Zr, Hf, Nb, $\mathrm{V}, \mathrm{Ta})$ solid solutions were predicted by the Debye model. 


\section{CHAPTER 5}

\section{Elastic properties}

The elastic parameters of materials are classified as elastic moduli for polycrystals and elastic stiffness or compliance for single crystals [114]. Elastic moduli are calculated using effective medium theories, such as the Reuss (lower bound, uniform strain) and Voigt (upper bound, uniform stress) averaging approaches [115, 116]. Hereby, a scheme is proposed to distinguish these elastic parameters [114]:

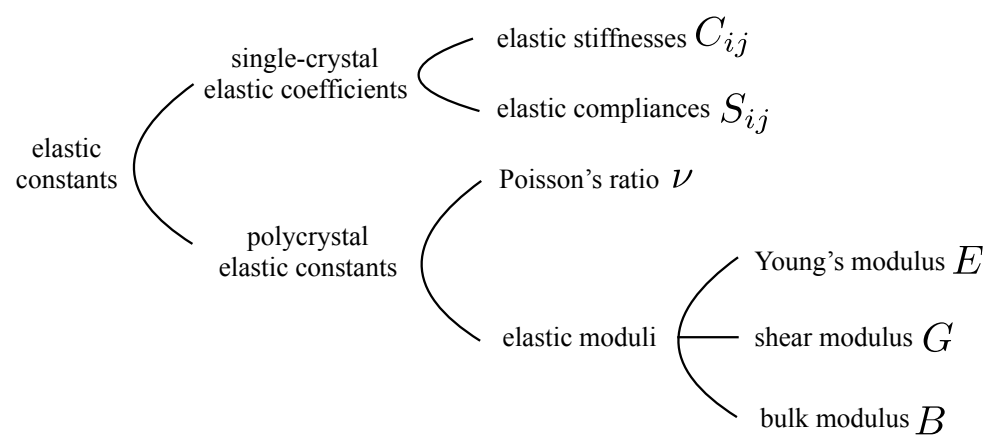

\subsection{Elastic properties of isotropic solids}

Deformation of materials changes the material's internal mechanical state. These changes are described by the strain and stress tensors; $\epsilon(\mathbf{r}), \sigma(\mathbf{r})$. $\epsilon$ defines the local distortion field in the material by

$$
\mathbf{r} \rightarrow \mathbf{r}^{\prime}=(\mathbb{1}+\epsilon(\mathbf{r})) \mathbf{r}
$$


and $\sigma$ describes the induced local internal forces per unit area $\mathbf{f}$ via

$$
f_{i}=\sum_{j=x, y, z} \sigma_{i j} n_{j}, \quad i=\{x, y, z\}
$$

where $\mathbf{n}$ is the normal vector of an arbitrary plane. The diagonal elements of $\sigma$ are called normal (or longitudinal, uniaxial) stresses while the off-diagonals are the shear ones. The eigenvalues of the stress tensor are called principal stresses. Hydrostatic or the isotropic stress condition is defined if $\sigma=p \mathbb{1}$, where the scalar $p$ is the mean stress or hydrostatic pressure. Any stress tensor can be split into a hydrostatic and a residual deviatoric component.

In the elastic (or linear) regime one defines the Young's $(E)$ and shear $(G)$ moduli of a material as

$$
\begin{aligned}
\sigma_{i i} & =E \epsilon_{i i}, \\
\sigma_{i j} & =G \epsilon_{i j} \quad i \neq j \quad i, j=\{x, y, z\}
\end{aligned}
$$

Young's modulus $(E)$ can be calculated also by $(F / A) /\left(d L / L_{0}\right)$, where $F$ is the applied force, $A$ is the cross area of the material with length $L_{0} . d L$ is the expansion of the material by the applied force. Thereby this modulus is commonly used as a measure of strength in engineering. Hydrostatic pressure causes a volume change $\Delta V$ of the material and then one defines the bulk modulus $B$ by

$$
p=B(-\Delta V / V)
$$

Beyond the ratio of $B / G$ introduced by Pugh [117] one plots an Ashby map [118] showing the material strength defined as $E / \rho$ versus $G / B$ to classify materials from mechanical engineering point of view, where $\rho$ is the materials density. The material is characterized as brittle if $G / B>0.57$ otherwise one says that the material is ductile (non-brittle).

\subsection{Elastic stiffness tensor}

The components of stress $\sigma_{i j}$ and strain $\epsilon_{i j}$ tensors are commonly written in $3 \times 3$ matrix form using Voigt's notation

$$
\sigma_{i j}=\left[\begin{array}{lll}
\sigma_{1} & \sigma_{6} & \sigma_{5} \\
\sigma_{6} & \sigma_{2} & \sigma_{4} \\
\sigma_{5} & \sigma_{4} & \sigma_{3}
\end{array}\right], \quad \varepsilon_{i j}=\left[\begin{array}{ccc}
\epsilon_{1} & 2 \epsilon_{6} & 2 \epsilon_{5} \\
2 \epsilon_{6} & \epsilon_{2} & 2 \epsilon_{4} \\
2 \epsilon_{5} & 2 \epsilon_{4} & \epsilon_{3}
\end{array}\right] .
$$

In case of elastic distortions Hook's law says that the stress is linearly related to the strain

$$
\sigma_{i j}=\sum_{k \ell} C_{i j k \ell} \epsilon_{k \ell}
$$

and the corresponding coefficient $C_{i j k \ell}$ is the 2nd-order elasticity stiffness tensor. The inverse of $C_{i j k \ell}$ is called the elastic compliance tensor. In the most general 
case of no symmetry, the number of elements in the elastic tensor is 21 . The amount of work made by an infinitesimal distortion $d \epsilon_{i}$ is written by

$$
d U=\sigma_{i} d \epsilon_{i}=V \sum_{j} C_{i j} \epsilon_{j} d \epsilon_{i}
$$

Therefore

$$
C_{i j}=\frac{1}{V} \frac{\partial}{\partial \varepsilon_{j}} \frac{\partial U}{\partial \varepsilon_{i}},
$$

which confirms also the symmetry of

$$
C_{i j}=C_{j i}
$$

One writes the symmetric elastic tensor in a $6 \times 6$ matrix form using Voigt's notation as,

$$
\left(\begin{array}{cccccc}
C_{11} & C_{12} & C_{13} & C_{14} & C_{15} & C_{16} \\
& C_{22} & C_{23} & C_{24} & C_{25} & C_{26} \\
& & C_{33} & C_{34} & C_{35} & C_{36} \\
& & & C_{44} & C_{45} & C_{46} \\
& & \ldots & & C_{55} & C_{56} \\
& & & & & C_{66}
\end{array}\right) .
$$

This full matrix is for the triclinic crystal symmetry class, which has only one symmetry operation, the unitary operation.

Based on Eq.(5.7), the elastic energy of a solid can be given by

$$
U=\frac{V}{2} \sum_{i=1}^{6} \sum_{j=1}^{6} C_{i j} \varepsilon_{i} \varepsilon_{j}=\frac{V}{2} \sum_{i=1}^{6} \sum_{j=1}^{6} S_{i j} \sigma_{i} \sigma_{j}
$$

\subsection{Elastic moduli of polycrystalline materials}

In the Voigt [116] approximation one assumes that the single crystal fibres are parallel to the stress axis subject to the same strain but with non-uniform stress, while the Reuss's assumption[115] means that the single crystal platelets are arranged in layers perpendicular to the stress axis with the uniform stress and non-uniform strain. The following expressions were obtained for the isotropic Polycrystalline elastic moduli:

$$
\begin{aligned}
& B_{V}=(1 / 3)(L+2 M) \\
& G_{V}=(1 / 5)(L-M+3 N) .
\end{aligned}
$$

where

$$
\begin{aligned}
L & =(1 / 3)\left(C_{11}+C_{22}+C_{33}\right), \\
M & =(1 / 3)\left(C_{12}+C_{23}+C_{13}\right), \\
N & =(1 / 3)\left(C_{44}+C_{55}+C_{66}\right) .
\end{aligned}
$$

and

$$
\begin{aligned}
& B_{R}=1 /\left(L^{\prime}+2 M^{\prime}\right), \\
& G_{R}=5 /\left(4 L^{\prime}-4 M^{\prime}+3 N^{\prime}\right) .
\end{aligned}
$$


where

$$
\begin{aligned}
L^{\prime} & =(1 / 3)\left(S_{11}+S_{22}+S_{33}\right), \\
M^{\prime} & =(1 / 3)\left(S_{12}+S_{23}+S_{13}\right), \\
N^{\prime} & =(1 / 3)\left(S_{44}+S_{55}+S_{66}\right) .
\end{aligned}
$$

Furthermore, the Young's Modulus is defined as

$$
E=\frac{9 B G}{3 B+G}
$$

The Poisson ratio $\nu$ is written as

$$
\nu=\frac{3 B-2 G}{6 B+2 G}
$$

In fact, the real physical value of these moduli should lie between the Voigt and Reuss averages $[115,116]$. Therefore an arithmetic average the Hill average is proposed [119].

$$
\begin{aligned}
B_{H} & =\frac{B_{V}+B_{R}}{2}, \\
G_{H} & =\frac{G_{V}+G_{R}}{2} .
\end{aligned}
$$

\subsection{Elastic properties of cubic disordered struc- tures}

The substitutional disorder used in the SQS approach (Chapter 3) breaks, in general, the point group symmetry of the underlying lattice. However, experimental investigations show that the symmetry of anisotropic materials quantities may not be altered by subtitutional alloying, or one measures polycrystalline constants, because one has ceramics that are polycrystalline. For example, the elastic stiffness tensor of c-TiAlN solid solution preserves the cubic symmetry of the parent materials, c-TiN and c-AlN. A symmetry based projection technique has been suggested $[103,120]$ to derive accurate prediction of the elastic tensor of substitutional alloys. For example, the symmetry projected cubic elastic stiffness constants are calculated as arithmetic averages:

$$
\begin{aligned}
& \bar{C}_{11}=\frac{C_{11}+C_{22}+C_{33}}{3}, \\
& \bar{C}_{12}=\frac{C_{12}+C_{13}+C_{23}}{3}, \\
& \bar{C}_{44}=\frac{C_{44}+C_{55}+C_{66}}{3},
\end{aligned}
$$

based on nine independent tensor elements: $C_{11}, C_{22}, C_{33}, C_{23}, C_{13}, C_{12}, C_{44}, C_{55}$ and $C_{66}$. A criterion for mechanical (not dynamical) stability of the crystal lattice is obtained from the condition that the energy density can be represented by 
a quadratic form defined positive so that the energy increases with any small deformation. Thus, the stability criteria of cubic crystals are given by:

$$
\bar{C}_{44}>0, \bar{C}_{11}>\left|\bar{C}_{12}\right|, \bar{C}_{11}+2 \bar{C}_{12}>0 \text {. }
$$

Cauchy relations are known as the relations between elastic constants [121]. In cubic case, it is $\bar{C}_{12}=\bar{C}_{44}$. The deviation from Cauchy relations indicates the deviation from the assumption of central forces.

A measure of elastic anisotropy can be given by:

$$
\bar{A}=2 \bar{C}_{44} /\left(\bar{C}_{11}-\bar{C}_{12}\right) .
$$

and the directional dependence of the Young's modulus [122] is written as

$$
\frac{1}{\bar{E}_{\ell_{1} \ell_{2} \ell_{3}}}=\bar{S}_{11}-2\left(\bar{S}_{11}-\bar{S}_{12}-\frac{1}{2} \bar{S}_{44}\right)\left(\ell_{1}^{2} \ell_{2}^{2}+\ell_{2}^{2} \ell_{3}^{2}+\ell_{1}^{2} \ell_{3}^{2}\right) .
$$

The 3 -tuple $\left(\ell_{1}, \ell_{2}, \ell_{3}\right)$ stands for the directional cosines to the $x, y$ and $z$ coordinate axes.

For cubic crystals, the polycrystalline elastic moduli are calculated using the expressions:

$$
\begin{aligned}
& B_{V}=B_{R}=\frac{\bar{C}_{11}+2 \bar{C}_{12}}{3}, \quad B_{H}=\frac{B_{V}+B_{R}}{2}, \\
& G_{V}=\frac{\left(\bar{C}_{11}-\bar{C}_{12}+3 \bar{C}_{44}\right)}{5}, \quad G_{R}=\frac{5 \bar{C}_{44}\left(\bar{C}_{11}-\bar{C}_{12}\right)}{4 \bar{C}_{44}+3\left(\bar{C}_{11}-\bar{C}_{12}\right)}, \quad G_{H}=\frac{G_{V}+G_{R}}{2}, \\
& E=\frac{9 B_{H} G_{H}}{3 B_{H}+G_{H}}, \quad \nu=\frac{3 B_{H}-2 G_{H}}{6 B_{H}+2 G_{H}}
\end{aligned}
$$

\subsection{Elastic Young's modulus of multilayers}

A linear-elasticity model of multilayers has been established with neglecting the interfacial heterogeneity [123]. Within our sharp interface approximation (see section 3.2), an analytic formula can be derived for the elastic stiffness constants of superlattices $C_{i j}^{\mathrm{SL}}$. We assume that the superlattice is built from the materials denoted by 1 and 2 . The fractions of materials 1 and 2 in the superlattice are written as $f_{1}$ and $f_{2}$. The stress and strain of the superlattice can be expressed as a function of the stress and strain of the individual layers:

$$
\sigma=f_{1} \sigma_{1}+f_{2} \sigma_{2}, \mu=f_{1} \mu_{1}+f_{2} \mu_{2},
$$

The constituent relations in each layer are

$$
\sigma_{i}=C_{i} \mu_{i}, i=1,2
$$

The effective elastic constant matrix of the superlattice is defined as

$$
\sigma=C \mu \text {. }
$$


Thus, the elastic stiffness constants of the superlattice are:

$$
C^{\mathrm{SL}}=\left(f_{1} \bar{C}_{1}^{\vec{n}} M+f_{2} \bar{C}_{2}^{\vec{n}}\right)\left(f_{1} M+f_{2} I\right)^{-1},
$$

where the interface normal vector is $\vec{n}$,

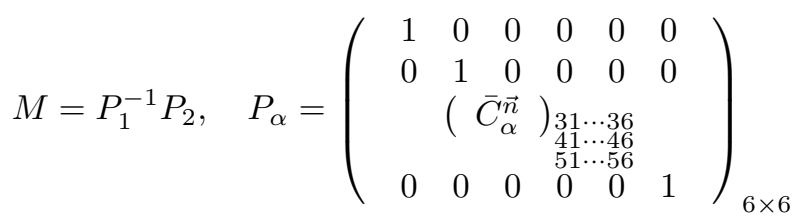

The Young's modulus of the multilayer in the normal direction to the interface is then given by

$$
E_{\vec{n}}=1 / S_{33}^{\mathrm{SL}}=\frac{C_{33}^{\mathrm{SL}}\left(C_{11}^{\mathrm{SL}}+C_{12}^{\mathrm{SL}}\right)-2 C_{13}^{\mathrm{SL}} C_{13}^{\mathrm{SL}}}{C_{11}^{\mathrm{SL}}+C_{12}^{\mathrm{SL}}}
$$




\section{CHAPTER 6}

\section{Density Functional Theory}

Density functional theory (DFT) is an exact approach to solve the quantum mechanical many body problem. The non-relativistic time-dependent Schrödinger equation

$$
i \frac{\mathrm{d} \Psi}{\mathrm{d} t}=\hat{H} \Psi
$$

gives the description of the dynamical behavior of a quantum system. $\hat{H}$ is the Hamiltonian of the system which is written in the case of a system of electrons and nuclei as

$$
\hat{H}=-\frac{1}{2} \sum_{i} \nabla_{i}^{2}-\sum_{I} \frac{1}{2 M_{I}} \nabla_{I}^{2}+\frac{1}{2} \sum_{i \neq j} \frac{1}{\left|\mathbf{r}_{i}-\mathbf{r}_{j}\right|}+\frac{1}{2} \sum_{I \neq J} \frac{Z_{I} Z_{J}}{\left|\mathbf{R}_{I}-\mathbf{R}_{J}\right|}-\sum_{i, I} \frac{Z_{I}}{\left|\mathbf{r}_{i}-\mathbf{R}_{I}\right|} .
$$

where the terms represent the kinetic energy of the electrons and the nuclei as well as the Coulomb interactions between electrons, nuclei and between electrons and nuclei. $M_{I}$ denotes the mass of the nuclei. $\mathbf{r}_{i}$ are the positions for the electrons. $\mathbf{R}_{I}$ and $Z_{I}$ stand for the positions and the charge number of the nuclei. For this Hamiltonian, the state of the system, the wave function is written as

$$
\Psi=\Psi\left(\mathbf{r}_{1}, \mathbf{r}_{2}, \mathbf{r}_{3}, \ldots, \mathbf{r}_{N}, \sigma_{1}, \sigma_{2}, \sigma_{3}, \ldots, \sigma_{N}, \mathbf{R}_{1}, \mathbf{R}_{2}, \mathbf{R}_{3}, \ldots, \mathbf{R}_{N}, t\right) .
$$

where $\sigma_{i}$ are the spin variables of the electrons.

The stationary states of the system are the eigen solutions of the time-independent Schrödinger equation, which can be written as

$$
\hat{H} \Psi=E \Psi .
$$

Eq.(6.2) has too many variables to solve it exactly and therefore approximations are essential in order to simplify the task. Since the nuclei are much heavier than 
the electrons, they move much slower and can be considered as "frozen" particles. This approximation is called Born-Oppenheimer approximation [124], in which one decouples the electronic freedoms from the freedoms of nuclei motion. Then the kinetic energy of the nuclei is constant and the Coulomb interactions between nuclei contribute as a constant term, which we can exclude when solving Eq.(6.4). The electron-nuclei interaction is then treated as an external field for the electrons. Therefore, the Hamiltonian of the electrons is given as

$$
\hat{H}_{e l e c}=-\frac{1}{2} \sum_{i} \nabla_{i}^{2}+\frac{1}{2} \sum_{i \neq j} \frac{1}{\left|\mathbf{r}_{i}-\mathbf{r}_{j}\right|}-\sum_{i, I} \frac{Z_{I}}{\left|\mathbf{r}_{i}-\mathbf{R}_{I}\right|} .
$$

In case of periodical systems, the wave function solutions to the Shrödinger equation has the form

$$
\psi_{n \mathbf{k}}(\mathbf{r})=e^{i \mathbf{k} \cdot r} u_{n \mathbf{k}}(\mathbf{r})
$$

where $n$ is the quantum number, $k$ is a reciprocal vector, $e^{i \mathbf{k} \cdot r}$ describes a plane wave and $u_{n \mathbf{k}}(\mathbf{r})$ is a function with the periodicity of the lattice. Even though the many body problem has been much simplified with all these approximations, solving the Schrödinger equation directly is still not practical. Hence, more reformulation of the problem should be done.

\subsection{Hohenberg-Kohn theorems}

The general idea of density functional theory (DFT) is to use the real electron density $n(\mathbf{r})$ as a basic variable instead of the complex wave function Eq.(6.3). The first attempt is known as Thomas-Fermi theory [125, 126], which was based on the density of a homogeneous electron gas for the kinetic energy and neglected both exchange and correlations among the electrons. Although Dirac extended the method with an approximation for the exchange [127], the theory was still inaccurate in most applications. In 1964, Hohenberg and Kohn [128] formulated two theorems, that have established the basis of modern density functional theory. The two theorems are stated as follows:

Theorem 1 For any system of interacting particles in an external potential $V_{\text {ext }}(\mathbf{r})$, the potential $V_{\text {ext }}(\mathbf{r})$ is uniquely determined, except an additive constant, by the ground state particle density $n_{0}(\mathbf{r})$.

Theorem 2 A universal functional for the energy $E[n]$ in terms of the density $n(\mathbf{r})$ can be defined, valid for any external potential $V_{\text {ext }}(\mathbf{r})$. For any particular $V_{\text {ext }}(\mathbf{r})$, the exact ground state energy of the system is the global minimum value of this functional, and the density $n(\mathbf{r})$ that minimizes the functional is the exact ground state density $n_{0}(\mathbf{r})$.

It is clear that the energy functional $E[n]$ determines the exact ground state energy and density, then the external potential on individual electrons is also obtained and with that all properties of the system can be derived. Therefore all that is needed is the energy functional $E[n]$. Its general form is written as:

$$
E[n]=T[n]+E_{i n t}[n]+\int d \mathbf{r} V_{e x t}(\mathbf{r}) n(\mathbf{r})+E_{i o n-i o n} .
$$


where the terms on the right are the kinetic energy of the electrons, the interaction energy between the electrons, the Coulomb interaction energy of electron density $n(\mathbf{r})$ with the external potential and the interaction energy between the nuclei. However, the forms of $T[n]$ and $E_{\text {int }}[n]$ are not known and a practical scheme is needed to solve the problem.

\subsection{Kohn-Sham equation}

Kohn and Sham [129] proposed replacing the interacting many-body system with non-interacting particles that move in an effective external field and have the same ground state density as the real system. The total energy of this non-interacting particles can be expressed with the density:

$$
E_{K S}[n]=T_{s}[n]+\int d \mathbf{r} V_{e x t}(\mathbf{r}) n(\mathbf{r})+E_{\text {Hartree }}[n]+E_{x c}[n]+E_{i o n-i o n} .
$$

where $T_{s}[n]$ is the kinetic energy of the non-interacting particles, given by:

$$
T_{s}[n]=-\frac{1}{2} \sum_{i=1}^{N}\left\langle\psi_{i}\left|\nabla^{2}\right| \psi_{i}\right\rangle .
$$

The electron density $n(\mathbf{r})$ in a system with $\mathrm{N}$ non-interacting electrons can be calculated as:

$$
n(\mathbf{r})=\sum_{i=1}^{N}\left|\psi_{i}(\mathbf{r})\right|^{2} .
$$

The effective potential acting on the non-interacting particles is

$$
V_{e f f}(\mathbf{r})=V_{e x t}(\mathbf{r})+\int d \mathbf{r}^{\prime} \frac{n\left(\mathbf{r}^{\prime}\right)}{\left|\mathbf{r}-\mathbf{r}^{\prime}\right|}+V_{x c}(\mathbf{r}) .
$$

The first term is the external potential, the second term is the Hartree potential describing the Coulomb interaction of an electron with a charge distribution $n(\mathbf{r})$, and the last term is the exchange-correlation potential:

$$
V_{x c}(\mathbf{r})=\frac{\delta E_{x c}[n(\mathbf{r})]}{\delta n(\mathbf{r})} .
$$

$\psi_{i}$ are the solutions of the single-particle Schödinger-like equation:

$$
\left(-\frac{1}{2} \nabla^{2}+V_{e f f}(\mathbf{r})\right) \psi_{i}(\mathbf{r})=\epsilon_{i} \psi_{i}(\mathbf{r}) .
$$

where $\epsilon_{i}$ is the eigenvalue of the non-interacting single particle.

$E_{\text {Hartree }}[n]$ is the Coulomb electrostatic potential energy of the electron density $n(\mathbf{r})$ with itself:

$$
E_{\text {Hartree }}[n]=\frac{1}{2} \iint d \mathbf{r} d \mathbf{r}^{\prime} \frac{n(\mathbf{r}) n\left(\mathbf{r}^{\prime}\right)}{\left|\mathbf{r}-\mathbf{r}^{\prime}\right|} .
$$

The trick is that those terms that vanish in a non-interacting, independent particle system are collected into an energy functional called exchange-correlation energy $E_{x c}[n]$. 


\subsection{Exchange-correlation functionals}

The simplest form of the exchange-correlation functional is the Local Density Approximation (LDA), first suggested in the original paper by Kohn and Sham. [129] The basic assumption is that the exchange-correlation energy at each spatial point $\mathbf{r}$ in space is equal to the exchange-correlation energy of a homogenous electron gas with the density $\epsilon_{x c}^{\text {hom }}(n(\mathbf{r}))$. The LDA exchange-correlation functional is thus calculated as:

$$
E_{x c}^{L D A}[n]=\int d \mathbf{r} n(\mathbf{r}) \epsilon_{x c}^{h o m}(n(\mathbf{r}))
$$

LDA is very accurate for the system with spatially slowly varying densities [130]. However, a weakness of LDA calculations is the overestimate of $E_{x c}[n(\mathbf{r})]$ for many systems resulting in underestimated lattice parameters, which may give rise to erroneous predictions of the ground state structure. The most cited failure of LDA is for $\mathrm{Fe}$, the prediction of the ground state structure is non-magnetic face-centered cubic (fcc), while in fact from experiments it is ferromagnetic body-centered cubic (bcc) [131]. Furthermore, LDA does not work for weak induced dipole-dipole interactions, such as Van der Waal's interactions.

An improvement of the LDA approximation is the Generalized Gradient approximation (GGA) [132],

$$
E_{x c}^{G G A}[n]=\int d \mathbf{r} n(\mathbf{r}) \epsilon_{x c}(n(\mathbf{r}), \nabla n(\mathbf{r})) .
$$

which takes into account not only the density $n(\mathbf{r})$ but also the density gradient $\nabla n$. The GGA approximation tends to underbind and it usually gives larger lattice constants compared to those obtained from experiments.

\subsection{Basis sets}

To solve the Kohn-Sham equations Eq.(6.13) numerically, the single-particle wavefunctions $\psi_{i}(\mathbf{r})$ need to be represented by a basis set. For crystalline solids, the atomic structure is periodic, a suitable choice of basis set is plane waves. However, $\psi_{i}(\mathbf{r})$ changes rapidly near the nuclei which requires a huge number of plane waves with high cutoff energy resulting in a very expensive computational cost.

The pseudopotential method $[133,134]$ is one attempt to solve the problem. The idea is to substitute the strong Coulomb potential by an effective ionic potential acting on the valence electrons, thus reducing the basis set size and computational time. The pseudopotential is constructed to provide the scattering properties of the core region and outside some cutoff radius, both the behavior of the valence wave functions and the effective potentials have to be the same as the exact ones. Norm-conserving [135] and Ultrasoft [136] pseudopotentials are two common used pseudopotentials.

An extension of the pseudopotential approach is the projector augmented wave (PAW) method, originally introduced by Blöchl [137] and further expanded by 
Kresse [138]. It is an all-electron method which retains the wave functions of the core states as well as applying the frozen core approximation. The full real electron wave function $\psi_{i}(\mathbf{r})$ is still available for total energy evaluations, the reliability and transferability of the potentials is thus increased.

In connection with the Coherent potential approximation (CPA), see Chapter 3, the Linear Muffin-Tin Orbital (LMTO) method [139] is used. The energy linearization of the Muffin-Tin Orbitals is put into a Hamiltonian formalism. The localized LMTO basis set, so called tight binding-LMTO was introduced by Andersen et al in 1984 [140]. The minimal basis produces a small Hamiltonian matrix, which makes calculations more efficient. 


\section{CHAPTER 7}

Results

\subsection{Thermodynamics stability}

\subsubsection{Mixing thermodynamics of cubic $\mathrm{Ti}_{1-x} \mathrm{Al}_{x} \mathrm{~N} / \mathrm{TiN}(001)$ multilayers}

Experimental results show extended age hardening by the spinodal decomposition of $\mathrm{Ti}_{1-x} \mathrm{Al}_{x} \mathrm{~N}$, the role of lattice coherency and interfacial chemistry on the driving force of this decomposition process is unexplored. Motivated by this, we choose cubic (B1) $\mathrm{Ti}_{1-x} \mathrm{Al}_{x} \mathrm{~N} / \mathrm{TiN}(001)$ multilayers as an example to investigate the mixing thermodynamics. Modeling alloys in multilayers and the calculation of mixing enthalpy in the $\mathrm{Ti}_{1-x} \mathrm{Al}_{x} \mathrm{~N} / \mathrm{TiN}(001)$ multilayer are introduced in details in Chapter 3.2,1 and 4.2. Here we discuss the multilayers with two different periodicities: 6 layers of $\mathrm{Ti}_{1-x} \mathrm{Al}_{x} \mathrm{~N}$ followed by 6 layers of TiN and 12 layers of $\mathrm{Ti}_{1-x} \mathrm{Al}_{x} \mathrm{~N}$ followed by 6 layers of $\mathrm{TiN}$.

The calculated mixing enthalpy values of $\mathrm{Ti}_{1-x} \mathrm{Al}_{x} \mathrm{~N}$ in multilayers (MLs) are shown in Figure 7.1, compared with the values obtained for the monolithic, bulk $\mathrm{Ti}_{1-x} \mathrm{Al}_{x} \mathrm{~N}$ case. The values are positive indicating a thermodynamic driving force towards phase separation. The ML curves show the same asymmetric tilting to higher compositions as in bulk $\mathrm{Ti}_{1-x} \mathrm{Al}_{x} \mathrm{~N}$. The multilayer mixing enthalpies are significantly suppressed with respect to bulk values, which means that the multilayer structure has a stabilization effect on $\mathrm{Ti}_{1-x} \mathrm{Al}_{x} \mathrm{~N}$. The decrease in the thicker $12 / 6$ multilayer is smaller as the overall system is closer to bulk $\operatorname{Ti}_{1-x} \mathrm{Al}_{x} \mathrm{~N}$. We propose that the stabilization effect can be split into a strain and an interfacial (or chemical) contribution, and both contributions are significant.

A method of calculating coherency strain effect on the mixing enthalpy is proposed, both the coherent in-plane lattice parameters and the modified lattice struc- 
ture along the (001) growth direction are considered. The mixing enthalpy with the coherency strain effect is shown in Figure 7.1. It is clear that the strain effect stabilizes the alloy, but does not give the full decrease of the mixing enthalpy. The rest of the stabilization effect is defined as the local interfacial or chemical contribution.

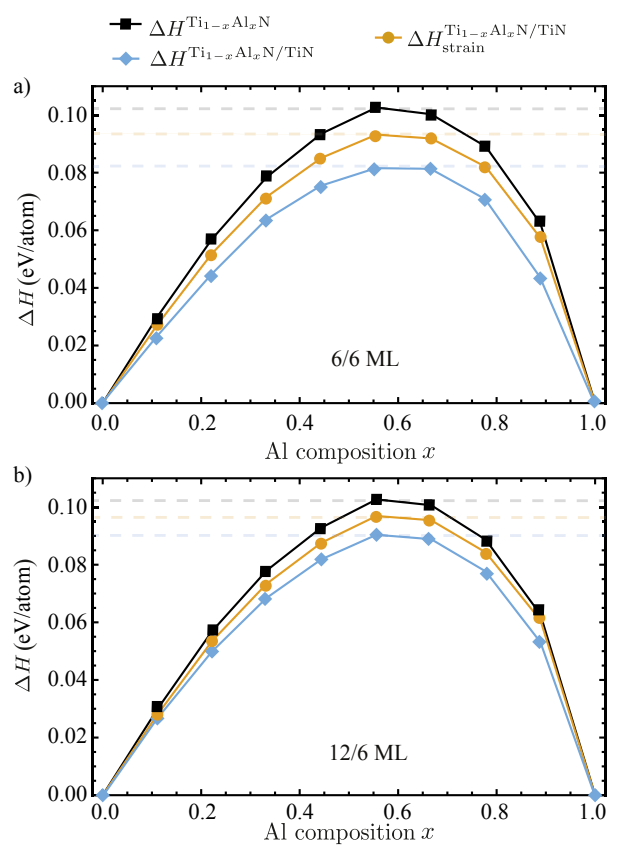

Figure 7.1. The mixing enthalpy of bulk $\mathrm{Ti}_{1-x} \mathrm{Al}_{x} \mathrm{~N}(\mathrm{ab}$ initio), the mixing enthalpy with the coherency strain effect and the mixing enthalpy(ab initio) of $\mathrm{Ti}_{1-x} \mathrm{Al}_{x} \mathrm{~N} / \mathrm{TiN}$ multilayer(ML). (a)6/6 ML (b)12/6 ML. The horizontal dashed lines show the maximum of the mixing enthalpy values for the bulk and the different multilayer cases.

The atomic relaxations were calculated and compared to the situation in bulk to see the effect of interfaces. With altered relaxations one expects a change in the effective cluster interactions. Figure 7.2 shows the relaxations of the $\mathrm{N}$ atoms along the $\mathrm{z}$ directions in each layer. The $\mathrm{z}$ coordinate is chosen because it is the interface orientation. The $\mathrm{N}$ atoms are distinguished by the different first neighborhood: Al-N-Al, Ti-N-Al, and Ti-N-Ti. The average shift of the relative distortions, shown by red line, gives that the TiAlN slab shrinks along $\mathrm{z}$, while the TiN slab expands. The internal, sub-plane with the $\mathrm{N}$ atoms surrounded only by $\mathrm{Al}$ atoms (noted as $\mathrm{Al}-\mathrm{N}-\mathrm{Al}$ ) has the largest shift. The Ti atoms in the TiN slab scatter wider in $\mathrm{z}$ direction than in $\mathrm{x}$ direction. The average relaxation of the $\mathrm{Ti}$ atoms does not follow the common trend which is the fitted straight line. For example, the $\mathrm{Ti}$ atoms in the last layer of the TiAlN slab have an increased amount of Ti first neighbors from layer 7 (TiN slab), which results in a stronger binding between the two layers via the Ti-d orbitals. Figure 7.3 shows the Ti-site d-orbital partial 

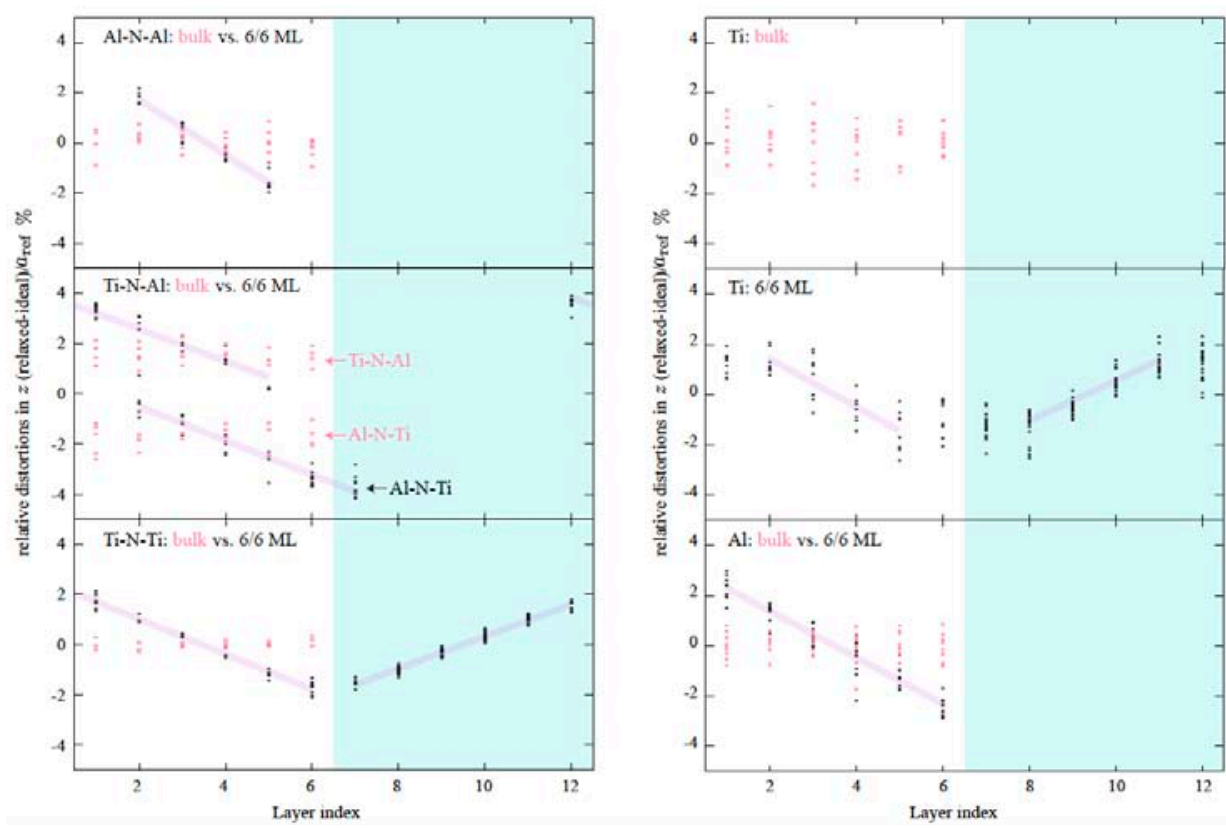

Figure 7.2. The atomic relaxations of the $\mathrm{N}$ atoms with different type of neighbors(Al$\mathrm{N}-\mathrm{Al}, \mathrm{Ti}-\mathrm{N}-\mathrm{Al}, \mathrm{Ti}-\mathrm{N}-\mathrm{Ti}) \mathrm{d}$ and the relaxations of the $\mathrm{Ti}$ and $\mathrm{Al}$ atoms along $z$ direction. The atomic relaxations are with respect to the ideal positions in each layer for $\mathrm{x}=0.55$ of bulk $\mathrm{Ti}_{1-x} \mathrm{Al}_{x} \mathrm{~N}$ and $6 / 6 \mathrm{ML}$.

density of states (PDOS) at the Fermi energy of the $\mathrm{Ti}_{1-x} \mathrm{Al}_{x} \mathrm{~N}$ slabs in the $6 / 6$ ML compared with the ones obtained in the bulk. In the multilayer form, one has lower PDOS values which means an increased Ti-Ti hybridization. Compared to the bulk, the electronic stabilization effect in the multilayer increases more with increasing the $\mathrm{Al}$ content, which correlates with the decreased tendency toward decomposition.

\subsubsection{Thermal stability of TiN/AlN and $\mathrm{ZrN} / \mathrm{AlN}$}

To explore the effect of forming semicoherent interfaces during film growth on the thermodynamic stability of multilayers, we propose to grow $\mathrm{TiN}$ or $\mathrm{ZrN}$ on $\mathrm{AlN}$ within different interfaces: cubic-(100)//cubic-(100), cubic-(110)//wurtzite-(1010), cubic-(111)//cubic-(111) and cubic-(111)//wurtzite-(0001). Figure 7.4 shows that for both $\mathrm{TiN} / \mathrm{AlN}$ and $\mathrm{ZrN} / \mathrm{AlN}$, the relative energy difference is low between isostructural coherent interfaces c-(100)//c-(100) and c-(111)//c-(111). The semicoherent interface, c-(110)//w-(10-10) is favorable for $\mathrm{ZrN} / \mathrm{AlN}$ but not for TiN/AlN. c-(111)//w-(0001) is energetically the most favorable interface for both material systems. Compared to isostructural coherent interfaces, the semicoherent interfaces have higher thermodynamic stability for $\mathrm{ZrN} / \mathrm{AlN}$, which matches the experimental observation of a high thermal stability of the film containing 


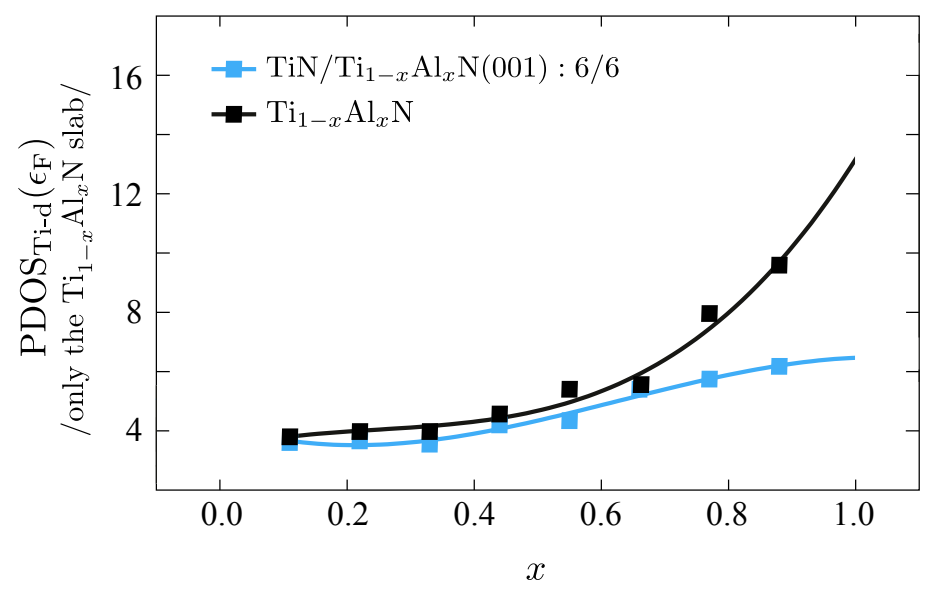

Figure 7.3. Bulk and the $6 / 6$ multilayer $d$-orbital partial density of states (PDOS) at the Fermi energy $\left(\epsilon_{\mathrm{F}}\right)$ of the Ti atoms from only the $\mathrm{Ti}_{1-x} \mathrm{Al}_{x} \mathrm{~N}$ slab.

semicoherent interfaces.

We also find that for $\mathrm{TiN} / \mathrm{AlN}$, the strain values are largest in case of c(110)//w-(10-10) and smallest for c-(111)//w-(0001). For $\mathrm{ZrN} / \mathrm{AlN}$, the largest strain is found for isostructural c-(100)//c-(100) and c-(111)//c-(111) interfaces, followed by c-(110)//w-(10-10) and smallest for $\mathrm{c}-(111) / / \mathrm{w}-(0001)$ interface. One can conclude that the higher thermodynamic stability of c-(111)//w-(0001) interface is related to the lower misfit strain, and the fact that AlN is in the stable wurtzite structure.

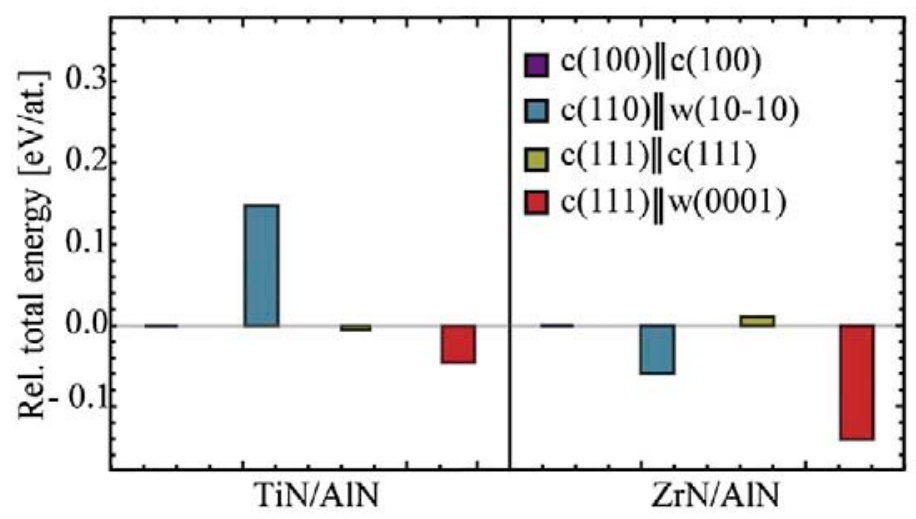

Figure 7.4. Ab-initio calculated total energy divided by 192 atoms (eV/atom) relative to c-(100)[001]//c-(100)[001] for TiN/AlN and ZrN/AlN multilayer. 


\subsection{Elastic properties}

\subsubsection{Alloys}

In Chapter 5, the symmetry projected cubic elastic stiffness constants are introduced and the polycrystalline elastic moduli can be calculated. Cauchy pressure $\left(\bar{C}_{12}-\bar{C}_{44}\right)$ indicates the character of atomic bonds, if it is negative the bonding is directional, while a positive value means delocalized rather metallic bonds. Figure 7.5 shows $G / B$ values and Cauchy pressure map of ternary $\mathrm{X}_{0.5} \mathrm{Al}_{0.5} \mathrm{~N}$ (1), $\mathrm{X}_{0.5} \mathrm{Ti}_{0.5} \mathrm{~N}(3)$ and quaternary alloys $\mathrm{X}_{0.33} \mathrm{Ti}_{0.33} \mathrm{Al}_{0.33} \mathrm{~N}(2)$ where $\mathrm{X}$ can be $\mathrm{Zr}$, $\mathrm{Hf}, \mathrm{V}, \mathrm{Nb}$ and Ta. Cubic AlN has covalent bonding and highly brittle behavior while cubic TaN is found as metallic and ductile material. Increased ductility is observed along the (0)-(2)-(3) lines and it is more clear for X from the VB metals than for IVB ones. The same behavior is noticed along the (0)-(2)-XN lines. Furthermore, ductility increases with the monotonous increase of the period number which means $3 d$ valence orbitals to $5 d$ ones. Decreasing Cauchy pressure indicates tendency toward stronger covalency in the atomic bonds, which results in increased resistance against shearing. The changes of shear modulus values $G$ correlate with the Cauchy pressure values.

To have a vivid picture of the elastic anisotropy, the directional dependence of the Young's modulus in each quaternary alloy is shown in Figure 7.6. A totally isotropic system would have a spherical shape, and the degree of geometric deviation from a sphere indicates the degree of anisotropy in a specific property of the system. The shapes of $\mathrm{Zr}_{0.33} \mathrm{Ti}_{0.33} \mathrm{Al}_{0.33} \mathrm{~N}, \mathrm{Hf}_{0.33} \mathrm{Ti}_{0.33} \mathrm{Al}_{0.33} \mathrm{~N}, \mathrm{~V}_{0.33} \mathrm{Ti}_{0.33} \mathrm{Al}_{0.33} \mathrm{~N}$ are a sphere, while there are deviations from sphere for the other phases. Such a feature of the $E$ shapes can be explained from considering significant difference in the nature of bonding behaviors with different components in the system.

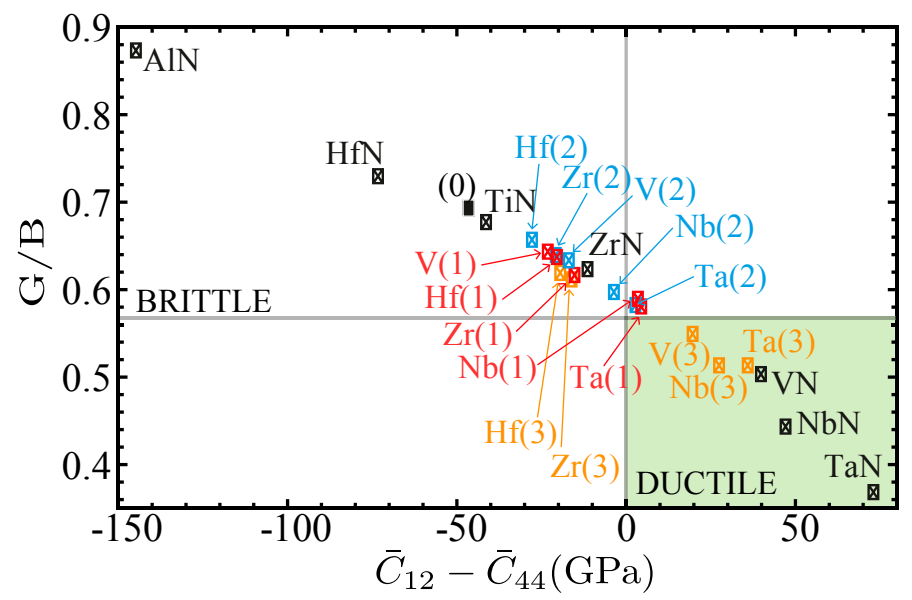

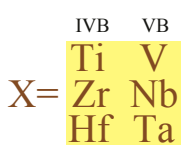

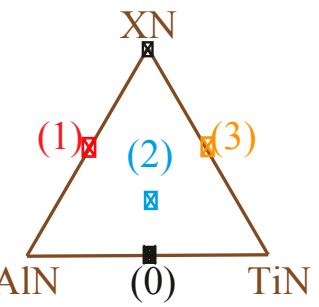

Figure 7.5. The $G / B$ vs. Cauchy pressure map of quaternary $\mathrm{X}_{y} \operatorname{Ti}_{(1-x-y)} \mathrm{Al}_{x} \mathrm{~N}$ alloys where $\mathrm{X}$ is $\mathrm{Zr}, \mathrm{Hf}, \mathrm{V}, \mathrm{Nb}$ and Ta. 


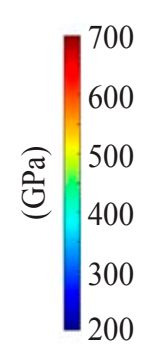

(a)
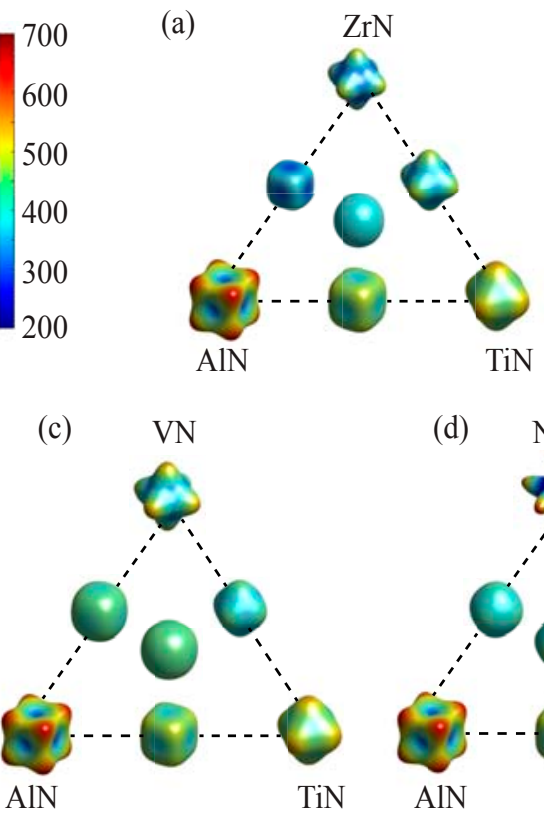

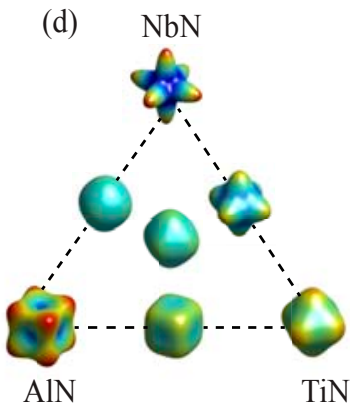

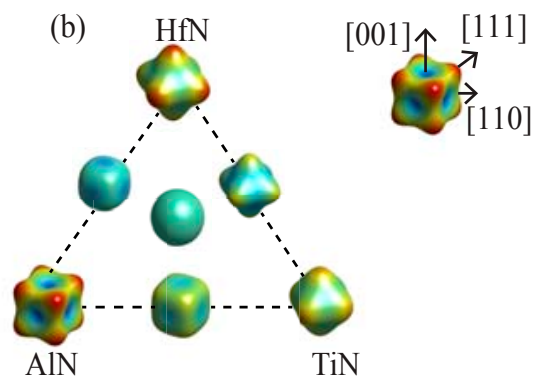

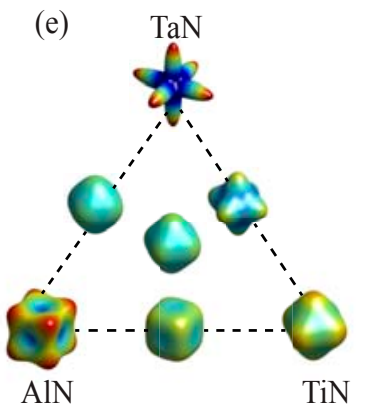

Figure 7.6. Three dimensional distribution of the Young's modulus in the quaternary $\mathrm{X}_{y} \mathrm{Ti}_{(1-x-y)} \mathrm{Al}_{x} \mathrm{~N}$ alloys where $\mathrm{X}$ is $\mathrm{Zr}, \mathrm{Hf}, \mathrm{V}, \mathrm{Nb}$ and $\mathrm{Ta}$.

\subsubsection{Multilayers}

The elastic constants of a multilayer are derived using the linear-elasticity model of superlattices in Chapter 5.5. The Young's modulus in the normal direction to the interface $E_{\vec{n}}$ of ternary and quaternary alloys coherently multilayered with TiN and $\mathrm{ZrN}$ binaries is shown in Figure 7.7. The values are for 1:1 fraction of the materials in the multilayer. $E_{\vec{n}}$ correlate with the ones in Figure 7.6 for all alloys and for both interfaces. The alloys multilayered with ZrN has lower Young's modulus values than the alloys multilayered with TiN. Due to the largest Young's modulus of HfN along [111] in Figure 7.6, HfN contained alloys in the (111) multilayers behave distinguished. Furthermore, $E_{\vec{n}}$ decreases with increasing TiN content with [111] interfacial orientation while it increases with increasing TiN content in [001] oriented multilayers. The high Young's modulus of all the transition metal nitrides in the dominant [001] direction determines the strength of the multilayers and therefore Young's modulus values are high for (001) multilayers, which we can conclude that one can estimate the variation of $E_{\vec{n}}$ based on Figure 7.6. Moreover, the multilayers with [111] orientations become more ductile with increasing TiN content while the increase of the $E_{\vec{n}}$ values with the TiN content in the (001) multilayers results in larger $\mathrm{G} / \mathrm{B}$ values, which predicts increased brittleness. 

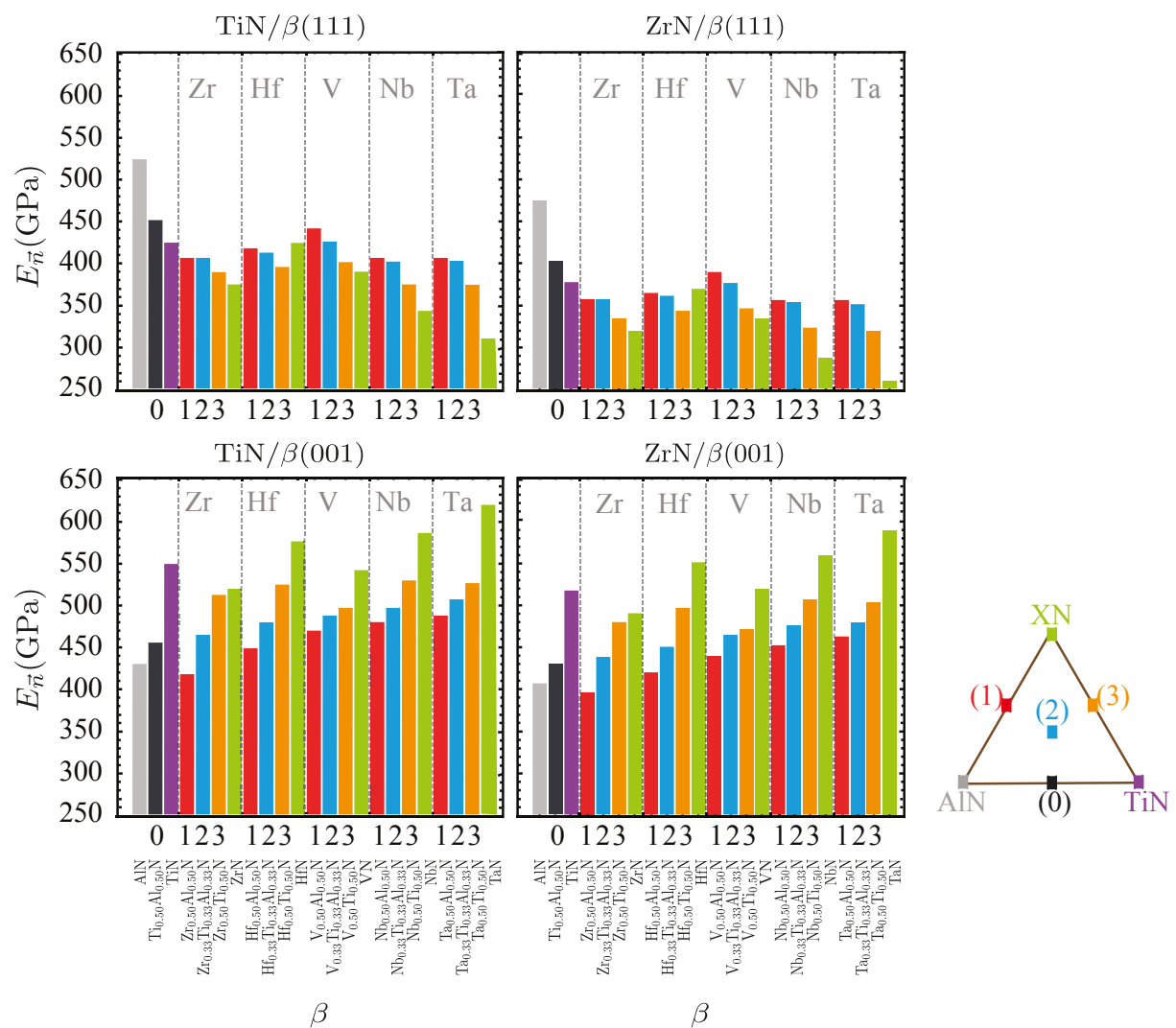

Figure 7.7. The Young's modulus perpendicular to the interface in coherent (001) and (111) directional TiN/XTiAlN and ZrN/XTiAlN multilayers where $\mathrm{X}$ is Zr, Hf, V, Nb and Ta. The values are give in GPa.

\subsection{Application of Debye model on multicompo- nent nitride alloys}

\subsection{1 $\mathrm{Ti}_{x} \mathrm{Nb}_{y} \mathrm{Al}_{z} \mathrm{~N}$ alloys}

With the method introduced in Chapter 3.3 and Chapter 4.3, the effect of $\mathrm{NbN}$ alloying on the high temperature behavior of $\mathrm{Ti}_{0.5} \mathrm{Al}_{0.5} \mathrm{~N}$ thin films is investigated. The mixing Gibbs free energy of cubic $\mathrm{Ti}_{x} \mathrm{Nb}_{y} \mathrm{Al}_{z} \mathrm{~N}$ (where $z=1-x-y$ ) alloys is calculated relative to the cubic B1 phases of TiN, NbN, and AlN at $1100 \mathrm{~K}$, which is shown in Figure 7.8. The mixing free energy of NbAlN and TiAlN is positive for all compositions, while it is negative for TiNbN, which indicates that NbAlN and TiAlN alloys are thermodynamically unstable and TiNbN is thermodynamically stable. The fact that NbAlN is unstable with a maximum in the $\mathrm{Al}$ rich end and TiNbN is stable with a minimum at equal $\mathrm{Nb}$ and $\mathrm{Ti}$ contents, determines the topology of the mixing Gibbs free energy surface. The mixing Gibbs free energy 
has a small positive value and it is in between two distinct free energy regions with positive and negative values of the mixing free energy. In this particular region the thermodynamic driving force (energy difference - chemical potential) is the same but with distinguished local environment or second derivative (topology). It is also clear from Figure 7.8 (a) that the inclusion of the vibrational contribution stabilizes the solid solution.

(a) - Debye model

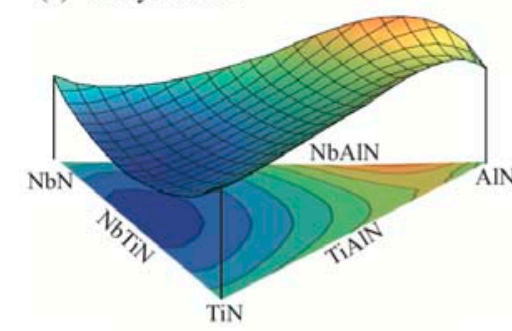

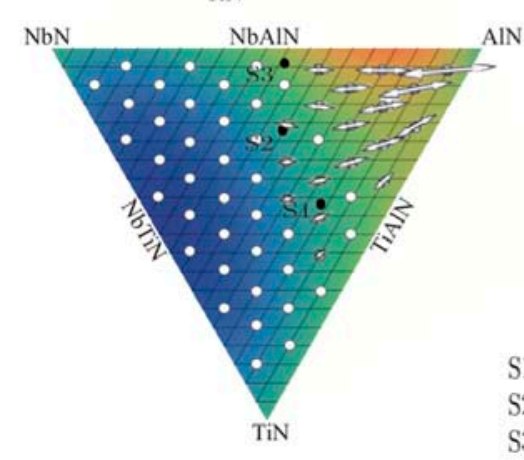

(b) - no vibrational entropy

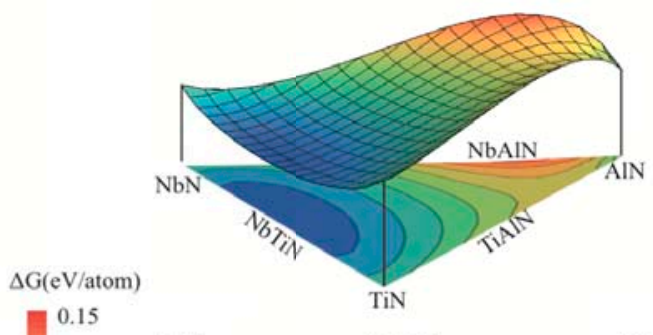

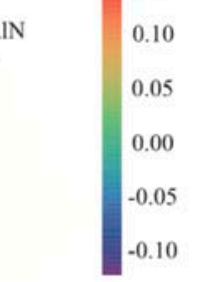

$\mathrm{S1}: \mathrm{Ti}_{0.42} \mathrm{Nb}_{0.17} \mathrm{Al}_{0.41} \mathrm{~N}$ $\mathrm{S} 2: \mathrm{Ti}_{0.22} \mathrm{Nb}_{0.36} \mathrm{Al}_{0.42} \mathrm{~N}$ $\mathrm{S} 3: \mathrm{Ti}_{0.03} \mathrm{Nb}_{0.45} \mathrm{Al}_{0.52} \mathrm{~N}$

Figure 7.8. The mixing free energy surface $\Delta G$ with arrows showing the local tendencies for spinodal decomposition in cubic $\mathrm{Ti}_{x} \mathrm{Nb}_{y} \mathrm{Al}_{z} \mathrm{~N}$ at $1100 \mathrm{~K}$. (a) shows $\Delta G$ with the inclusion of phonon contribution approximated through the Debye model while (b) displays $\Delta G$ with configurational entropy only. The arrows represent the most favorable directions of local spinodal decomposition. The lengths of the arrows are proportional to the magnitudes of the second derivatives, which indicate the strength of the decomposition. In the low $\mathrm{Al}$ content part of the diagram where the alloy is stable, there is no driving force for spinodal decomposition, which is marked by open circles.

For multicomponent alloys, to predict their mixing thermodynamics at high temperature, one needs an effective approach. Figure 7.9 shows the mixing energetics of $\mathrm{Ti}_{1-x} \mathrm{Al}_{x} \mathrm{~N}$ solid solutions calculated at $1500 \mathrm{~K}$. In a) one sees a comparison of the Gibbs free energy obtained by TDEP (the temperature dependent effective potential method which includes the effects of anharmonicity) and by the quasi-harmonic Debye model using elastic constants calculated for $\mathrm{x}=0.0$, 0.5 and 1.0 at $0 \mathrm{~K}$. In b) one sees the vibrational contribution to $G_{\operatorname{mix}}$ in both, TDEP and the quasi-harmonic Debye model. It underlines that Debye model can be assumed to greatly increase the efficiency of simulations and work fine for the class of multicomponent nitride coatings. 
a)

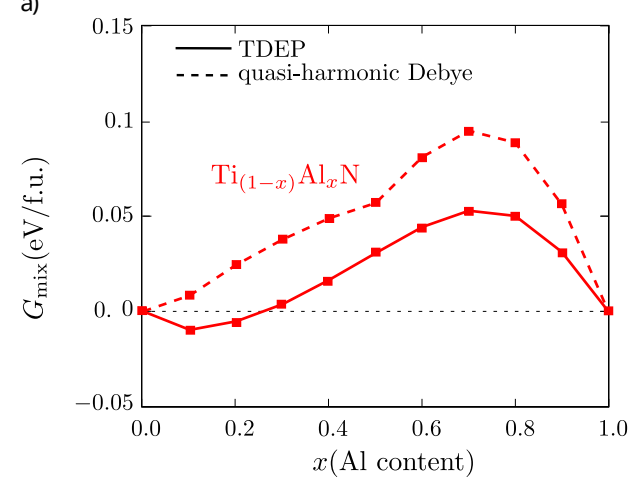

b)

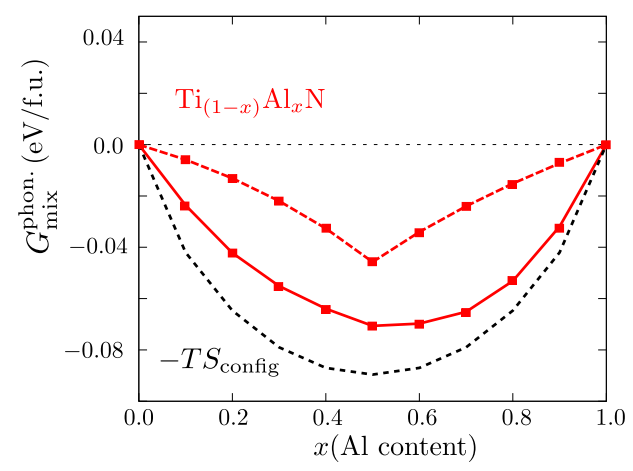

Figure 7.9. Mixing energetics of $\mathrm{Ti}_{1-x} \mathrm{Al}_{x} \mathrm{~N}$ solid solutions calculated at $1500 \mathrm{~K}$. a) shows $G_{\text {mix }}$ obtained by TDEP method with solid lines and the dashed lines show the results of the quasi-harmonic Debye model. In b) the lines display the vibration contribution to $G_{\text {mix }}$ in both, TDEP and the present quasi-harmonic Debye model with elastic constants calculated for $x=0.0,0.5$ and 1.0.

Spinodal decomposition will occur if the second derivative of Gibbs free energy is negative. For a ternary alloy, a two-dimensional second directional derivative should be considered for determining the local spinodal decomposition behavior and the decomposition will start in the direction with the largest negative value of the second derivative. The spinodal decomposition trends of $\mathrm{Ti}_{x} \mathrm{Nb}_{y} \mathrm{Al}_{z} \mathrm{~N}$ alloys are shown in Figure 7.8 with arrows. It is interesting that vibrational contribution strongly affects the thermodynamic stability of the solution phases, but not the favorable local tendencies for the spinodal decomposition. Three experimental samples, S1: $\mathrm{Ti}_{0.42} \mathrm{Nb}_{0.17} \mathrm{Al}_{0.41} \mathrm{~N}$, S2: $\mathrm{Ti}_{0.22} \mathrm{Nb}_{0.36} \mathrm{Al}_{0.42} \mathrm{~N}$, S3: $\mathrm{Ti}_{0.03} \mathrm{Nb}_{0.45} \mathrm{Al}_{0.52} \mathrm{~N}$ were deposited in the interesting region. The arrows sizes are slowly changing in the vicinity of S1 while they show a more significant variations around S3. It suggests different thermal stabilities against spinodal decomposition for the samples. The calculations indicate that rapid low temperature spinodal decomposition should occur in S3, which results in significant age hardening though with low temperature stability. For S1 high temperature stability is predicted, higher than for 
S2 and S3. Furthermore, no TiN and NbN are expected during the decomposition.

\subsubsection{Thermal expansion coefficients of $\mathrm{Ti}_{1-x-y} \mathrm{X}_{y} \mathrm{Al}_{x} \mathbf{N}(\mathrm{X}$ $=\mathrm{Zr}, \mathrm{Hf}, \mathrm{Nb}, \mathrm{V}, \mathrm{Ta})$}

In Paper VI, the thermal expansion coefficients (TEC) of multicomponent cubic nitride alloys $\mathrm{Ti}_{1-x-y} \mathrm{X}_{y} \mathrm{Al}_{x} \mathrm{~N}(\mathrm{X}=\mathrm{Zr}, \mathrm{Hf}, \mathrm{Nb}, \mathrm{V}, \mathrm{Ta})$ are predicted with the quasiharmonic Debye approximation of phonons through the ab initio calculated $0 \mathrm{~K}$ elastic constants. A direct benchmark of the approximation against TDEP in predicting TEC has been shown with TiN and $\mathrm{Ti}_{1-x} \mathrm{Al}_{x} \mathrm{~N}$.

The linear thermal expansion coefficients of cubic quaternary $\mathrm{Ti}_{1-x-y} \mathrm{Hf}_{y} \mathrm{Al}_{x} \mathrm{~N}$ and $\mathrm{Ti}_{1-x-y} \mathrm{Ta}_{y} \mathrm{Al}_{x} \mathrm{~N}$ solid solutions at 600,900 and $1200 \mathrm{~K}$ with the quasi-harmonic Debye approximation are shown in Figure 7.10. The values increase with the temperature and present a monotonous increase with $\mathrm{X}$ amount at all temperatures in $\mathrm{Ti}_{1-x-y} \mathrm{Ta}_{y} \mathrm{Al}_{x} \mathrm{~N}$. For $\mathrm{Ti}_{1-x-y} \mathrm{Hf}_{y} \mathrm{Al}_{x} \mathrm{~N}$ alloys, the highest value of TEC is shown in the $\mathrm{Al}$ rich vicinity of $\mathrm{Hf}_{0.5} \mathrm{Al}_{0.5} \mathrm{~N}$.
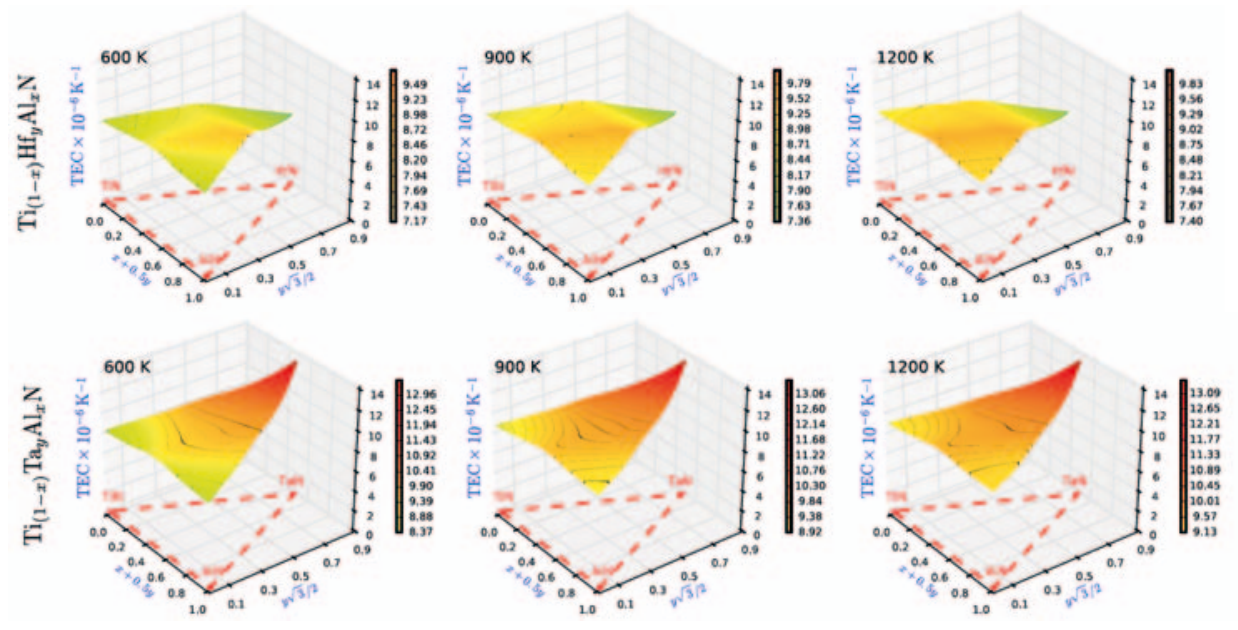

Figure 7.10. The linear thermal expansion coefficients (TEC) of cubic quaternary $\mathrm{Ti}_{1-x-y} \mathrm{Hf}_{y} \mathrm{Al}_{x} \mathrm{~N}$ and $\mathrm{Ti}_{1-x-y} \mathrm{Ta}_{y} \mathrm{Al}_{x} \mathrm{~N}$ solid solutions at 600,900 and $1200 \mathrm{~K}$ with the Debye approximation. 


\section{CHAPTER 8}

\section{Conclusions and Outlook}

My research presented here has explored the most important properties of nitride alloys for high-temperature industrial cutting applications. I illustrated the power of theoretical investigations as guidance to tailor design novel materials and consolidate the motto "The right material for right application".

We demonstrate that $\mathrm{Ti}_{1-x} \mathrm{Al}_{x} \mathrm{~N}$ solid solution is stabilized by interfacial effects if it is coherently sandwiched between TiN layers along (001). Motivated by this, I would investigate the thermodynamics in case of semicoherent multilayers.

The Debye model is used in this thesis to reveal the high-temperature thermodynamics and spinodal decomposition of $\mathrm{Ti}_{x} \mathrm{Nb}_{y} \mathrm{Al}_{1-x-y} \mathrm{~N}$ and predict the thermal expansion coefficients of $\mathrm{Ti}_{x} \mathrm{X}_{y} \mathrm{Al}_{1-x-y} \mathrm{~N}(\mathrm{X}=\mathrm{Zr}, \mathrm{Hf}, \mathrm{Nb}, \mathrm{V}, \mathrm{Ta})$. The impact of phonons on the mixing energetics and the thermal expansion of multilayers are expected to be captured with reasonable (for industry) accuracy by the efficient quasi-harmonic Debye model. A fairly complex project would be to establish a simulation framework in which one considers a finite interfacial thickness $(2-3 \mathrm{~nm})$ with compositional profile that is observed by atom probe tomography.

We also calculated the elastic constants of cubic $\mathrm{Ti}_{x} \mathrm{X}_{y} \mathrm{Al}_{1-x-y} \mathrm{~N}$ (X=Zr, Hf, $\mathrm{Nb}, \mathrm{V}, \mathrm{Ta}$ ) solid solutions and their multilayers. An analytic comparison of strengths and ductility is presented to reveal the potential of these materials in hard coating applications. A linear-elasticity model of superlattices instead of performing computationally demanding calculations is proposed to derive the elastic constants and obtain the Young's modulus, which is one of the important engineering parameter for experiments. In the next step, this method could be applied to other superlattices. It is also possible to develop a further model on multilayers including disordered alloys. 


\section{Bibliography}

[1] Materials Genome Initiative. 2011. URL: https://www.mgi.gov/.

[2] Novel Materials Discovery. 2015. URL: https://www.nomad-coe.eu/.

[3] A. Knutsson et al. "Thermally enhanced mechanical properties of arc evaporated $\mathrm{Ti}_{0.34} \mathrm{Al}_{0.66} \mathrm{~N} / \mathrm{TiN}$ multilayer coatings". In: J. Appl. Phys. 108.4 (2010), p. 044312.

[4] Jeffrey H. Nguyen and Neil C. Holmes. "Melting of iron at the physical conditions of the Earth's core". In: Nature 427 (2004), pp. 339-342.

[5] A. Hörling et al. "Thermal stability of arc evaporated high aluminumcontent $\mathrm{Ti}_{1-x} \mathrm{Al}_{x} \mathrm{~N}$ thin films". In: J. Vac. Sci. Technol. A Vacuum, Surfaces, Film. 20.5 (2002), p. 1815.

[6] Staffan Söderberg. "Advances in coating technology for metal cutting tools". In: Met. Powder Rep. 56.4 (2001), pp. 24-30.

[7] Wolf-Dieter Münz. "Titanium aluminum nitride films: A new alternative to TiN coatings". In: J. Vac. Sci. Technol. A Vacuum, Surfaces, Film. 4.6 (1986), p. 2717.

[8] I. Vurgaftman, J. R. Meyer, and L. R. Ram-Mohan. "Band parameters for III-V compound semiconductors and their alloys". In: J. Appl. Phys. 89.11 I (2001), pp. 5815-5875.

[9] M A Moram and M E Vickers. "X-ray diffraction of III-nitrides". In: Reports Prog. Phys. 72.3 (2009), p. 036502.

[10] A Siegel, K Parlinski, and U Wdowik. "Ab initio calculation of structural phase transitions in AlN crystal". In: Phys. Rev. B 74.10 (2006), pp. 1-6.

[11] N E Christensen and I Gorczyca. "Optical and structural properties of III-V nitrides under pressure". In: Phys. Rev. B 50.7 (1994), pp. 4397-4415. 
[12] Wen Tai Lin et al. "Epitaxial growth of cubic AlN films on (100) and (111) silicon by pulsed laser ablation". In: Appl. Phys. Lett. 66.16 (1995), pp. 2066-2068.

[13] A. Madan et al. "Stabilization of Cubic AlN in Epitaxial AlN/TiN Superlattices". In: Phys. Rev. Lett. 78.9 (1997), pp. 1743-1746.

[14] F. Adibi et al. "Defect structure and phase transitions in epitaxial metastable cubic $\mathrm{Ti}_{0.5} \mathrm{Al}_{0.5} \mathrm{~N}$ alloys grown on $\mathrm{MgO}(001)$ by ultra-high-vacuum magnetron sputter deposition". In: J. Appl. Phys. 69.9 (1991), pp. 6437-6450.

[15] A. Knutsson et al. "Machining performance and decomposition of TiAlN/TiN multilayer coated metal cutting inserts". In: Surf. Coatings Technol. 205.16 (2011), pp. 4005-4010.

[16] "Powder diffraction files 03-065-0565 (TiN)". In: International center for diffraction data (2007).

[17] A Flink, T Larsson, and J. Sjölén. "Influence of Si on the microstructure of arc evaporated ( $\mathrm{Ti}, \mathrm{Si}$ ) N thin films; evidence for cubic solid solutions and their thermal stability". In: Surf. Coatings Technol. 200.5-6 (2005), pp. 1535-1542.

[18] "Powder diffraction files 00- 035-0753 ( $\mathrm{ZrN}$ )". In: International center for diffraction data (2007).

[19] H Holleck. "Metastable coatings - Prediction of composition and structure". In: Surf. Coatings Technol. 36.1-2 (1988), pp. 151-159.

[20] S.H. Sheng, R.F. Zhang, and S. Veprek. "Phase stabilities and thermal decomposition in the $\mathrm{Zr}_{1-x} \mathrm{Al}_{x} \mathrm{~N}$ system studied by ab initio calculation and thermodynamic modeling". In: Acta Mater. 56.5 (2008), pp. 968-976.

[21] K.A. Gruss et al. "Characterization of zirconium nitride coatings deposited by cathodic arc sputtering". In: Surf. Coatings Technol. 107.2-3 (1998), pp. 115-124.

[22] E. W. Niu et al. "Influence of substrate bias on the structure and properties of $\mathrm{ZrN}$ films deposited by cathodic vacuum arc". In: Mater. Sci. Eng. A 460461 (2007), pp. 135-139.

[23] "Powder diffraction files 00-033-0592 (HfN)". In: International center for diffraction data (2007).

[24] H. S. Seo et al. "Epitaxial and polycrystalline Hf $\mathrm{Nx}(0.8 \leq \mathrm{x} \leq 1.5)$ layers on $\mathrm{MgO}(001)$ : Film growth and physical properties". In: J. Appl. Phys. 97.8 (2005), pp. 0-9.

[25] B. Howe et al. "Growth and physical properties of epitaxial metastable $\mathrm{Hf}_{1-x} \mathrm{Al}_{x} \mathrm{~N}$ alloys deposited on $\mathrm{MgO}(001)$ by ultrahigh vacuum reactive magnetron sputtering". In: Surf. Coatings Technol. 202.4-7 (2007), pp. 809814.

[26] R. Armitage et al. "Lattice-matched HfN buffer layers for epitaxy of GaN on Si". In: Appl. Phys. Lett. 81.8 (2002), pp. 1450-1452. 
[27] X. Xu et al. "Epitaxial condition and polarity in GaN grown on a HfNbuffered Si(111) wafer". In: Appl. Phys. Lett. 86.18 (2005), pp. 1-3.

[28] Anna Delin et al. "Optical properties of the group-IVB refractory metal compounds." In: Phys. Rev. B. Condens. Matter 54.3 (1996), pp. 16731681.

[29] "Powder diffraction files 00-035-0768 (VN". In: International center for diffraction data (2007).

[30] F I Ajami and R K Maccrone. "Magnetic Susceptibility and Superconductivity of Cubic Vanadium Nitrides". In: J. Phys. Chem. Solids 36 (1975), pp. $7-15$.

[31] Daiwon Choi, George E. Blomgren, and Prashant N. Kumta. "Fast and reversible surface redox reaction in nanocrystalline vanadium nitride supercapacitors". In: Adv. Mater. 18.9 (2006), pp. 1178-1182.

[32] Xiaoping Zhou et al. "Study on the electrochemical behavior of vanadium nitride as a promising supercapacitor material". In: J. Phys. Chem. Solids 70.2 (2009), pp. 495-500.

[33] V.N. Zhitomirsky et al. "Structure and mechanical properties of vacuum arc-deposited NbN coatings". In: Thin Solid Films 326.1-2 (1998), pp. 134142.

[34] "Powder diffraction files 03-065-5011 (NbN)". In: International center for diffraction data (2007).

[35] Zhen Wang et al. "Superconducting properties and crystal structures of single-crystal niobium nitride thin films deposited at ambient substrate temperature". In: J. Appl. Phys. 79.10 (1996), pp. 7837-7842.

[36] "Powder diffraction files 03-065-9404 (TaN)". In: International center for diffraction data (2007).

[37] M. H. Tsai et al. "Comparison of the diffusion barrier properties of chemicalvapor-deposited TaN and sputtered TaN between $\mathrm{Cu}$ and Si". In: J. Appl. Phys. 79.9 (1996), pp. 6932-6938.

[38] S. Shibata, K. Murasugi, and K. Kaminishi. "New Type Thermal Printing Head Using Thin Film". In: IEEE Trans. Parts, Hybrids, Packag. 12.3 (1976), pp. 223-230.

[39] Kazuo Eda et al. "Miniature hybrid microwave IC's using a novel thin-film technology". In: IEEE Trans. Microw. Theory Tech. 38.12 (1990), pp. 19491956.

[40] E. I. Isaev et al. "Phonon related properties of transition metals, their carbides, and nitrides: A first-principles study". In: J. Appl. Phys. 101.12 (2007), p. 123519.

[41] Hermann A. Jehn et al. "Morphology and properties of sputtered ( $\mathrm{Ti}, \mathrm{Al}) \mathrm{N}$ layers on high speed steel substrates as a function of deposition temperature and sputtering atmosphere". In: J. Vac. Sci. Technol. A Vacuum, Surfaces, Film. 4.6 (1986), p. 2701. 
[42] O. Knotek, M. Böhmer, and T. Leyendecker. "On structure and properties of sputtered Ti and Al based hard compound films". In: J. Vac. Sci. Technol. A Vacuum, Surfaces, Film. 4.1986 (1986), p. 2695.

[43] U. Wahiström et al. "Crystal growth and microstructure of polycrystalline $\mathrm{Ti}_{1-x} \mathrm{Al}_{x} \mathrm{~N}$ alloy films deposited by ultra-high-vacuum dual-target magnetron sputtering". In: Thin Solid Films 235.1-2 (1993), pp. 62-70.

[44] Min Zhou et al. "Phase transition and properties of Ti-Al-N thin films prepared by r.f.-plasma assisted magnetron sputtering". In: Thin Solid Films 339.1-2 (1999), pp. 203-208.

[45] Paul H. Mayrhofer et al. "Self-organized nanostructures in the Ti-Al-N system". In: Appl. Phys. Lett. 83.10 (2003), p. 2049.

[46] B Alling et al. "Comparison of thermodynamic properties of cubic $\mathrm{Cr}_{1-x} \mathrm{Al}_{x} \mathrm{~N}$ and $\mathrm{Ti}_{1-x} \mathrm{Al}_{x} \mathrm{~N}$ from first-principles calculations". In: J. Appl. Phys. 102.4 (2007), p. 044314.

[47] A. Hörling et al. "Mechanical properties and machining performance of $\mathrm{Ti}_{1-x} \mathrm{Al}_{x} \mathrm{~N}$-coated cutting tools". In: Surf. Coatings Technol. 191.2-3 (2005), pp. 384-392.

[48] P H Mayrhofer, D Music, and J M Schneider. "Ab initio calculated binodal and spinodal of cubic $\mathrm{Ti}_{1-x} \mathrm{Al}_{x}$ N". In: Appl. Phys. Lett. 88.7 (2006), p. 071922.

[49] RF Zhang and S Veprek. "Metastable phases and spinodal decomposition in $\mathrm{Ti}_{1-x} \mathrm{Al}_{x} \mathrm{~N}$ system studied by ab initio and thermodynamic modeling, a comparison with the $\mathrm{TiN}_{-} \mathrm{Si}_{3} \mathrm{~N}_{4}$ system". In: Mater. Sci. Eng. A 448.1-2 (2007), pp. 111-119.

[50] B. Alling et al. "Mixing and decomposition thermodynamics of c- $\mathrm{Ti}_{1-x} \mathrm{Al}_{x} \mathrm{~N}$ from first-principles calculations". In: Phys. Rev. B 75.4 (2007), p. 045123.

[51] R Rachbauer et al. "Decomposition pathways in age hardening of Ti-Al-N films". In: J. Appl. Phys. 110.2 (2011), p. 023515.

[52] Hiroyuki Hasegawa, Masahiro Kawate, and Tetsuya Suzuki. "Effects of Al contents on microstructures of $\mathrm{Cr}_{1-x} \mathrm{Al}_{x} \mathrm{~N}$ and $\mathrm{Zr}_{1-x} \mathrm{Al}_{x} \mathrm{~N}$ films synthesized by cathodic arc method". In: Surf. Coatings Technol. 200.7 (2005), pp. 24092413.

[53] R Lamni et al. "Microstructure and nanohardness properties of Zr-Al-N and Zr-Cr-N thin films". In: J. Vac. Sci. Technol. A 23.4 (2005), pp. 593-598.

[54] L. Rogström et al. "Influence of chemical composition and deposition conditions on microstructure evolution during annealing of arc evaporated ZrAlN thin films". In: J. Vac. Sci. Technol. A Vacuum, Surfaces, Film. 30.3 (2012), p. 031504 .

[55] L. Rogström et al. "Thermal stability and mechanical properties of arc evaporated ZrN/ZrAlN multilayers". In: Thin Solid Films 519.2 (2010), pp. 694699. 
[56] L. Rogström et al. "Age hardening in arc-evaporated ZrAlN thin films". In: Scr. Mater. 62.10 (2010), pp. 739-741.

[57] Naureen Ghafoor et al. "Nanolabyrinthine ZrAlN thin films by self-organization of interwoven single-crystal cubic and hexagonal phases". In: APL Mater. 1.2 (2013), p. 022105.

[58] Björn Alling, A Karimi, and I.A. Abrikosov. "Electronic origin of the isostructural decomposition in cubic $\mathrm{M}_{1-x} \mathrm{Al}_{x} \mathrm{~N}(\mathrm{M}=\mathrm{Ti}, \mathrm{Cr}, \mathrm{Sc}, \mathrm{Hf})$ : A first-principles study". In: Surf. Coatings Technol. 203.5-7 (2008), pp. 883-886.

[59] David Holec et al. "Phase stability and alloy-related trends in Ti-Al-N , ZrAl-N and Hf-Al-N systems from first principles". In: Surf. Coat. Technol. 206.7-5 (2011), pp. 1698-1704.

[60] R. Franz et al. "Investigation on structure and properties of arc-evaporated HfAlN hard coatings". In: J. Vac. Sci. Technol. A Vacuum, Surfaces, Film. 28.4 (2010), p. 528.

[61] B.M. Howe et al. "Real-time control of AlN incorporation in epitaxial $\mathrm{Hf}_{1-x} \mathrm{Al}_{x} \mathrm{~N}$ using high-flux, low-energy (10-40eV) ion bombardment during reactive magnetron sputter deposition from a $\mathrm{Hf}_{0.7} \mathrm{Al}_{0.3}$ alloy target". In: Acta Mater. 59.2 (2011), pp. 421-428.

[62] Szilárd Kolozsvári et al. "Deposition and characterization of hard coatings in the material system $\mathrm{V}-\mathrm{Al}-\mathrm{N}$ by reactive magnetron sputter deposition". In: Plasma Process. Polym. 6 (2009), pp. 146-151.

[63] Ping Zhu et al. "Microstructure, chemical states, and mechanical properties of magnetron co-sputtered $\mathrm{V}_{1-x} \mathrm{Al}_{x} \mathrm{~N}$ coatings". In: Surf. Coatings Technol. 232 (2013), pp. 311-318.

[64] Florian Rovere et al. "Experimental and computational study on the phase stability of Al-containing cubic transition metal nitrides". In: J. Phys. D. Appl. Phys. 43.3 (2010), p. 035302.

[65] TI Selinder et al. "Phase formation and microstructure of $\mathrm{Nb}_{1-x} \mathrm{Al}_{x} \mathrm{~N}$ alloy films grown on $\mathrm{MgO}$ (001) by reactive sputtering: a new ternary phase". In: Vacuum 46.12 (1995), pp. 1401-1406.

[66] Harish C. Barshilia et al. "Structure and properties of reactive direct current magnetron sputtered niobium aluminum nitride coatings". In: J. Mater. Res. 23.05 (2008), pp. 1258-1268.

[67] R. Franz et al. "Tribological Properties of Arc-Evaporated NbAlN Hard Coatings". In: Tribol. Lett. 45.1 (2012), pp. 143-152.

[68] R. Franz et al. "Structure, mechanical properties and oxidation behaviour of arc-evaporated NbAlN hard coatings". In: Surf. Coatings Technol. 204.15 (2010), pp. 2447-2453.

[69] David Holec et al. "Structure and stability of phases within the NbN-AlN system". In: J. Phys. D. Appl. Phys. 43.14 (2010), p. 145403. 
[70] C.M. Koller et al. "Thermal stability and oxidation resistance of arc evaporated TiAlN, TaAlN, TiAlTaN, and TiAlN/TaAlN coatings". In: Surf. Coatings Technol. 259 (2014), pp. 599-607.

[71] O. Knotek, W. Burgmer, and C. Stoessel. "Arc-evaporated Ti-V-N thin films". In: Surf. Coatings Technol. 54-55 (1992), pp. 249-254.

[72] A. Hoerling et al. "Thermal stability, microstructure and mechanical properties of $\mathrm{Ti}_{1-x} \mathrm{Zr}_{x} \mathrm{~N}$ thin films". In: Thin Solid Films 516.18 (2008), pp. 64216431 .

[73] V.V. Uglov et al. "Structural and mechanical stability upon annealing of arc-deposited Ti-Zr-N coatings". In: Surf. Coatings Technol. 202.11 (2008), pp. 2394-2398.

[74] K. Vasu, M. Ghanashyam Krishna, and K. A. Padmanabhan. "Effect of Nb concentration on the structure, mechanical, optical, and electrical properties of nano-crystalline $\mathrm{Ti}_{1-x} \mathrm{Nb}_{x} \mathrm{~N}$ thin films". In: J. Mater. Sci. 47.8 (2012), pp. 3522-3528.

[75] I Grimberg et al. "Multicomponent Ti-Zr-N and Ti-Nb-N coatings deposited by vacuum arc". In: Surf. Coatings Technol. 108-109 (1998), pp. 154-159.

[76] G. Abadias et al. "Reactive magnetron cosputtering of hard and conductive ternary nitride thin films: Ti-Zr-N and Ti-Ta-N". In: J. Vac. Sci. Technol. A Vacuum, Surfaces, Film. 28.4 (2010), p. 541.

[77] G. M. Matenoglou et al. "Structure, stability and bonding of ternary transition metal nitrides". In: Surf. Coatings Technol. 204.6-7 (2009), pp. 911914.

[78] M.A. Roldán, M.D. Alcalá, and C. Real. "Characterisation of ternary $\operatorname{Ti}_{x}$ $\mathrm{V}_{1-x} \mathrm{~N}_{y}$ nitride prepared by mechanosynthesis". In: Ceram. Int. 38.1 (2012), pp. 687-693.

[79] O. Knotek. "Industrial deposition of binary, ternary, and quaternary nitrides of titanium, zirconium, and aluminum". In: J. Vac. Sci. Technol. A Vacuum, Surfaces, Film. 5.4 (1987), p. 2173.

[80] V.V. Uglov et al. "Stability of Ti-Zr-N coatings under Xe-ion irradiation". In: Surf. Coatings Technol. 204.12-13 (2010), pp. 2095-2098.

[81] L. E. Koutsokeras et al. "Conducting transition metal nitride thin films with tailored cell sizes: The case of $\delta-\mathrm{Ti}_{x} \mathrm{Ta}_{1-x} \mathrm{~N}$ ". In: Appl. Phys. Lett. 93.1 (2008), p. 011904.

[82] G. M. Matenoglou et al. "Structure and electronic properties of conducting, ternary $\mathrm{Ti}_{x} \mathrm{Ta}_{1-x} \mathrm{~N}$ films". In: J. Appl. Phys. 105.10 (2009), p. 103714.

[83] Paul H. Mayrhofer et al. "Microstructural design of hard coatings". In: Prog. Mater. Sci. 51.8 (2006), pp. 1032-1114.

[84] $\mathrm{H}$ Lind et al. "Improving thermal stability of hard coating films via a concept of multicomponent alloying". In: Appl. Phys. Lett. 99.9 (2011), p. 091903. 
[85] Rikard Forsén et al. "Decomposition and phase transformation in TiCrAlN thin coatings". In: J. Vac. Sci. Technol. A Vacuum, Surfaces, Film. 30.6 (2012), p. 061506.

[86] David Holec et al. "Alloying-related trends from first principles: An application to the Ti-Al-X-N system". In: J. Appl. Phys. 113.11 (2013), p. 113510.

[87] Li Chen et al. "Influence of Zr on structure, mechanical and thermal properties of Ti-Al-N". In: Thin Solid Films 519.16 (2011), pp. 5503-5510.

[88] S.A. Glatz et al. "Thermal stability and mechanical properties of arc evaporated Ti-Al-Zr-N hard coatings". In: Surf. Coatings Technol. 266 (2015), pp. 1-9.

[89] R Rachbauer et al. "Effect of Hf on structure and age hardening of Ti-Al-N thin films". In: Surf. Coatings Technol. 206.10 (2012), pp. 2667-2672.

[90] Yu X. Xu et al. "Influence of Hf on the structure, thermal stability and oxidation resistance of Ti-Al-N coatings". In: Thin Solid Films 565 (2014), pp. 25-31.

[91] K. Kutschej et al. "A new low-friction concept for $\mathrm{Ti}_{1-x} \mathrm{Al}_{x} \mathrm{~N}$ based coatings in high-temperature applications". In: Surf. Coatings Technol. 188-189.2004 (2004), pp. 358-363.

[92] M Pfeiler et al. "The influence of bias voltage on structure and mechanical/tribological properties of arc evaporated Ti-Al-V-N coatings". In: Surf. Coatings Technol. 202.4-7 (2007), pp. 1050-1054.

[93] Robert Franz and Christian Mitterer. "Vanadium containing self-adaptive low-friction hard coatings for high-temperature applications: A review". In: Surf. Coatings Technol. 228 (2013), pp. 1-13.

[94] R. Rachbauer, D. Holec, and P.H. Mayrhofer. "Increased thermal stability of Ti-Al-N thin films by Ta alloying". In: Surf. Coatings Technol. 211 (2012), pp. 98-103.

[95] Richard Rachbauer et al. "Electronic origin of structure and mechanical properties in Y and $\mathrm{Nb}$ alloyed Ti-Al-N thin films". In: Int. J. Mater. Res. 102.6 (2011), pp. 735-742.

[96] M. Pfeiler et al. "Arc Evaporation of Ti-Al-Ta-N Coatings: The Effect of Bias Voltage and Ta on High-temperature Tribological Properties". In: Tribol. Lett. 30.2 (2008), pp. 91-97.

[97] A. Knutsson et al. "Thermal decomposition products in arc evaporated TiAlN/TiN multilayers". In: Appl. Phys. Lett. 93.14 (2008), p. 143110.

[98] A. Knutsson et al. "Microstructure evolution during the isostructural decomposition of TiAlN-A combined in-situ small angle x-ray scattering and phase field study". In: J. Appl. Phys. 113.21 (2013), p. 213518.

[99] Alex Zunger et al. "Special quasirandom structures". In: Phys. Rev. Lett. 65.3 (1990), pp. 353-356.

[100] Paul Soven. "Coherent-Potential Model of Substitutional Disordered Alloys". In: Phys. Rev. 156.3 (1967), pp. 809-813. 
[101] J. M. Cowley. "An Approximate Theory of Order in Alloys". In: Phys. Rev. 77.5 (1990), pp. 669-675.

[102] A V Ruban and I A Abrikosov. "Configurational thermodynamics of alloys from first principles: effective cluster interactions". In: Reports Prog. Phys. 71.4 (2008), p. 046501.

[103] Maher Moakher and Andrew N. Norris. "The Closest Elastic Tensor of Arbitrary Symmetry to an Elasticity Tensor of Lower Symmetry". In: J. Elast. 85.3 (2006), pp. 215-263.

[104] Ferenc Tasnádi, M. Odén, and Igor A. Abrikosov. "Ab initio elastic tensor of cubic $\mathrm{Ti}_{0.5} \mathrm{Al}_{0.5} \mathrm{~N}$ alloys: Dependence of elastic constants on size and shape of the supercell model and their convergence". In: Phys. Rev. B 85.14 (2012), p. 144112 .

[105] V. Ozoliiňš, C Wolverton, and Alex Zunger. "Effects of anharmonic strain on the phase stability of epitaxial films and superlattices: Applications to noble metals". In: Phys. Rev. B 57.8 (1998), pp. 4816-4828.

[106] D W Taylor. "Vibrational Properties of Imperfect Crystals with Large Defect Concentrations". In: Phys. Rev. 156.3 (1967), pp. 1017-1029.

[107] J Korringa. "On the calculation of the energy of a Bloch wave in a metal". In: Physica 13.6-7 (1947), pp. 392-400.

[108] W. Kohn and N. Rostoker. "Solution of the Schrödinger Equation in Periodic Lattices with an Application to Metallic Lithium". In: Phys. Rev. 94.5 (1954), pp. 1111-1120.

[109] B. L. Györffy. "Coherent-Potential Approximation for a NonoverlappingMuffin-Tin-Potential Model of Random Substitutional Alloys". In: Phys. Rev. B 5.6 (1972), pp. 2382-2384.

[110] A. V. Ruban and H. L. Skriver. "Screened Coulomb interactions in metallic alloys. I. Universal screening in the atomic-sphere approximation". In: Phys. Rev. B 66.2 (2002), p. 024201.

[111] A. V. Ruban et al. "Local lattice relaxations in random metallic alloys: Effective tetrahedron model and supercell approach". In: Phys. Rev. B 67.21 (2003), p. 214302.

[112] A.V. Ruban and H.L. Skriver. "Calculated surface segregation in transition metal alloys". In: Comput. Mater. Sci. 15.2 (1999), pp. 119-143.

[113] R.E. Newnham. Properties of materials, Anisotropy, symmetry, Structure. Oxford University Press, 2005.

[114] Göran Grimvall. Thermophysical properties of materials. ELSEVIER SCIENCE, 1999.

[115] A Reuss. "Berechnung der Fließgrenze von Mischkristallen auf Grund der Plastizitätsbedingung für Einkristalle". In: Z. Angew Math. Phys. 9.49 (1929).

[116] N Voigt. "Ueber adiabatische Elasticitätsconstanten". In: Ann. Phys. (Leipz.) 38.573 (1889). 
[117] S.F. Pugh. "Relations between the elastic moduli and the plastic properties of polycrystalline pure metals". In: Philos. Mag. Ser. 745.367 (1954), pp. 823-843.

[118] William Art Counts et al. "Ab Initio Guided Design of bcc Ternary Mg-Li$\mathrm{X}(\mathrm{X}=\mathrm{Ca}, \mathrm{Al}, \mathrm{Si}, \mathrm{Zn}, \mathrm{Cu})$ Alloys for Ultra-Lightweight Applications". In: Adv. Eng. Mater. 12.7 (2010), pp. 572-576.

[119] R Hill. "The Elastic Behaviour of a Crystalline Aggregate". In: Proc. Phys. Soc. Sect. A 65.5 (1952), pp. 349-354.

[120] Jules Thomas Browaeys and Sébastien Chevrot. "Decomposition of the elastic tensor and geophysical applications". In: Geophys. J. Int. 159.2 (2004), pp. 667-678.

[121] K.Huang and M.Born. Dynamical theory of crystal lattices. Oxford University Press, London, 1954.

[122] John F Nye. Physical properties of crystals. Oxford Clarendon, 1985.

[123] M. Grimsditch. "Effective elastic constants of superlattices". In: Phys. Rev. B 31.10 (1985), pp. 6818-6819.

[124] M. Born and R. Oppenheimer. "Zur Quantentheorie der Molekeln". In: Ann. Phys. 389.20 (1927), pp. 457-484.

[125] L. H. Thomas. "The calculation of atomic fields". In: Math. Proc. Cambridge Philos. Soc. 23.05 (1927), p. 542.

[126] E. Fermi. "Un metodo statistico per la determinazione di alcune priorietà dell'atome". In: Rend. Accad. Naz. Lincei 6 (1927), pp. 602-607.

[127] P. A. M. Dirac. "Note on Exchange Phenomena in the Thomas Atom". In: Math. Proc. Cambridge Philos. Soc. 26.03 (1930), p. 376.

[128] P. Hohenberg and W. Kohn. "Inhomogeneous Electron Gas". In: Phys. Rev. 136.3B (1964), B864-B871.

[129] W. Kohn and L. J. Sham. "Self-Consistent Equations Including Exchange and Correlation Effects". In: Phys. Rev. 140.4A (1965), A1133-A1138.

[130] Kieron Burke, John P Perdew, and Matthias Ernzerhof. "Why semilocal functionals work: Accuracy of the on-top pair density and importance of system averaging". In: J. Chem. Phys. 109.10 (1998), pp. 3760-3771.

[131] C. S. Wang, B. M. Klein, and H. Krakauer. "Theory of Magnetic and Structural Ordering in Iron". In: Phys. Rev. Lett. 54.16 (1985), pp. 1852-1855.

[132] John P. Perdew, Kieron Burke, and Matthias Ernzerhof. "Generalized Gradient Approximation Made Simple". In: Phys. Rev. Lett. 78.7 (1997), pp. 1396 1396 .

[133] H. Hellmann. "A New Approximation Method in the Problem of Many Electrons". In: J. Chem. Phys. 3.1 (1935), pp. 61-61.

[134] H. Hellmann and W. Kassatotschkin. "Metallic Binding According to the Combined Approximation Procedure". In: J. Chem. Phys. 4.5 (1936), pp. 324325 . 
[135] D. R. Hamann, M. Schlüter, and C. Chiang. "Norm-Conserving Pseudopotentials". In: Phys. Rev. Lett. 43.20 (1979), pp. 1494-1497.

[136] David Vanderbilt. "Soft self-consistent pseudopotentials in a generalized eigenvalue formalism". In: Phys. Rev. B 41.11 (1990), pp. 7892-7895.

[137] P. E. Blöchl. "Projector augmented-wave method". In: Phys. Rev. B 50.24 (1994), pp. 17953-17979.

[138] G. Kresse and D. Joubert. "From ultrasoft pseudopotentials to the projector augmented-wave method". In: Phys. Rev. B 59.3 (1999), pp. 1758-1775.

[139] O. K. Andersen. "Simple approach to the band-structure problem". In: Solid State Communications 13.2 (1973), pp. 133-136.

[140] O. K. Andersen and O. Jepsen. "Explicit, First-Principles Tight-Binding Theory". In: Phys. Rev. Lett. 53 (1984), pp. 2571-2574. 


\section{List of included publications and my contribution}

[I] Special quasirandom structure method in application for advanced properties of alloys: A study on $\mathbf{T i}_{0.5} \mathrm{Al}_{0.5} \mathbf{N}$ and $\mathrm{TiN} / \mathbf{T i}_{0.5} \mathbf{A l}_{0.5} \mathbf{N}$ multilayer

Ferenc Tasnádi, Fei Wang, Magnus Odén, Igor A. Abrikosov.

Computational Materials Science, 103, 194-199 (2015).

I took part in performing some calculations, did some data analysis, participated in part of the evaluation and interpretation of the results.

[II] Coherency effects on the mixing thermodynamics of cubic $\operatorname{Ti}_{1-x} \mathbf{A l}_{x} \mathbf{N}$ $/ \mathrm{TiN}(001)$ multilayers

Fei Wang, Igor A. Abrikosov, Sergei I. Simak, Magnus Odén, Frank Mücklich, Ferenc Tasnádi.

PHYSICAL REVIEW B, 93, 174201 (2016).

I took part in planning of the project, performed all the calculations, did all the data analysis, participated in the evaluation and interpretation of the results, and wrote the manuscript.

[III] Growth and thermal stability of TiN/ZrAlN: Effect of internal interfaces

Kumar Yalamanchili, Fei Wang, Hisham Aboulfadl, Jenifer Barrirero, Lina Rogström, Emilio Jiménez-Pique, Frank Mücklich, Ferenc Tasnádi, Magnus Odén, Naureen Ghafoor.

Acta Materialia, 121, 396-406 (2016),

I took part in part of planning of the project, performed all the calculations, did all the data analysis of calculations, participated part of the evaluation 
and interpretation of the results, and wrote part of the manuscript.

[IV] Systematic ab initio investigation of the elastic modulus in quaternary transition metal nitride alloys and in their coherent multilayers

Fei Wang, David Holec, Magnus Odén, Frank Mücklich, Igor A. Abrikosov, Ferenc Tasnádi.

Acta Materialia, 127, 124-132 (2017).

I took part in planning of the project, performed all the calculations, did all the data analysis, participated in the evaluation and interpretation of the results, and wrote the manuscript.

[V] High temperature thermodynamics of spinodal decomposition in arc deposited $\mathbf{T i}_{x} \mathbf{N b}_{y} \mathbf{A l}_{z} \mathbf{N}$ coatings

Ferenc Tasnádi, Lina Rogström, Jianqiang Zhu, Fei Wang, T.-W. Hsu, Hans Lind, Igor A. Abrikosov, M. P. Johansson-Jõesaar, Magnus Odén.

Submitted to Materials and Design.

I took part in part of planning of the project, performed all the calculations, did all the data analysis of calculations, participated part of the evaluation and interpretation of the results.

[VI] Thermal expansion of quaternary nitride coatings Ferenc Tasnádi, Fei Wang, Magnus Odén, Igor A. Abrikosov.

Submitted to APL materials.

I performed some calculations, did some data analysis of calculations, participated part of the evaluation and interpretation of the results. 
Related, not included publications

[I] Exploring the high entropy alloy concept in (AlTiVNbCr)N

K. Yalamanchili, Fei Wang, Isabella Schramm, J. M. Andersson, Mats P. Johansson Jöesaar, Ferenc Tasnádi, Frank Mücklich, Naureen Ghafoor and Magnus Odén.

Thin Solid Films, 636, 346-352 (2017).

[II] Effects of configurational disorder on the elastic properties of icosahedral boron-rich alloys based on $\mathrm{B}_{6} \mathrm{O}, \mathrm{B}_{13} \mathrm{C}_{2}$, and $\mathrm{B}_{4} \mathrm{C}$, and their mixing thermodynamics.

A. Ektarawong, S. I. Simak, L. Hultman, J. Birch, F. Tasnádi, F. Wang and B. Alling.

The Journal of Chemical Physics, 144, 134503 (2016). 


\section{Papers}

The papers associated with this thesis have been removed for copyright reasons. For more details about these see:

http://urn.kb.se/resolve?urn=urn:nbn:se:liu:diva-145091 